\title{
Orally Administered Exosomes Suppress Mouse Delayed-Type Hypersensitivity by Delivering miRNA-150 to Antigen-Primed Macrophage APC Targeted by Exosome-Surface Anti-Peptide Antibody Light Chains
}

\author{
Katarzyna Nazimek ${ }^{1,2,+}\left(\mathbb{D}\right.$, Krzysztof Bryniarski ${ }^{1,2, *,+}\left(\mathbb{D}\right.$, Wlodzimierz Ptak ${ }^{1, \ddagger}$, \\ Tom Groot Kormelink ${ }^{2}$ and Philip W. Askenase 2,*(D) \\ 1 Department of Immunology, Faculty of Medicine, Medical College, Jagiellonian University, 31-121 Krakow, \\ Poland; katarzyna.nazimek@uj.edu.pl \\ 2 Section of Rheumatology, Allergy and Immunology, Department of Internal Medicine, School of Medicine, \\ Yale University, New Haven, CT 06520-8013, USA; t.grootkormelink@amc.uva.nl \\ * Correspondence: mmbrynia@cyf-kr.edu.pl (K.B.); philip.askenase@yale.edu (P.W.A.); \\ Tel.: +48-12-632-58-65 (K.B.); +1-203-809-2031 (P.W.A.) \\ + These authors contributed equally. \\ $\ddagger$ Deceased.
}

Received: 16 July 2020; Accepted: 1 August 2020; Published: 2 August 2020

check for updates

\begin{abstract}
We previously discovered suppressor T cell-derived, antigen (Ag)-specific exosomes inhibiting mouse hapten-induced contact sensitivity effector $\mathrm{T}$ cells by targeting antigen-presenting cells (APCs). These suppressive exosomes acted Ag-specifically due to a coating of antibody free light chains (FLC) from Ag-activated B1a cells. Current studies are aimed at determining if similar immune tolerance could be induced in cutaneous delayed-type hypersensitivity (DTH) to the protein Ag (ovalbumin, OVA). Intravenous administration of a high dose of OVA-coupled, syngeneic erythrocytes similarly induced $\mathrm{CD} 3^{+} \mathrm{CD} 8^{+}$suppressor $\mathrm{T}$ cells producing suppressive, miRNA-150-carrying exosomes, also coated with B1a cell-derived, OVA-specific FLC. Simultaneously, OVA-immunized B1a cells produced an exosome subpopulation, originally coated with Ag-specific FLC, that could be rendered suppressive by in vitro association with miRNA-150. Importantly, miRNA-150-carrying exosomes from both suppressor $\mathrm{T}$ cells and B1a cells efficiently induced prolonged DTH suppression after single systemic administration into actively immunized mice, with the strongest effect observed after oral treatment. Current studies also showed that OVA-specific FLC on suppressive exosomes bind OVA peptides suggesting that exosome-coating FLC target APCs by binding to peptide-Ag-major histocompatibility complexes. This renders APCs capable of inhibiting DTH effector T cells. Thus, our studies describe a novel immune tolerance mechanism mediated by FLC-coated, Ag-specific, miRNA-150-carrying exosomes that act on the APC and are particularly effective after oral administration.
\end{abstract}

Keywords: antibody free light chains (FLC); delayed-type hypersensitivity (DTH); extracellular vesicles (EVs); exosomes; miRNA; miRNA-150; oral therapy; suppressor T cells

\section{Introduction}

Recent studies have shown that immune regulation in vivo is more diverse than previously appreciated. A unique antigen (Ag)-specificity of $\mathrm{T}$ cell immunosuppression was described previously in contact sensitivity (CS) induced by epicutaneous immunization of mice with reactive hapten [1-5]. 
This form of Ag-specific T cell tolerance is systemically generated by intravenous (IV) administration of high doses of hapten-conjugated syngeneic erythrocytes, followed by skin sensitization with the same reactive hapten. This induces $\mathrm{CD}^{+}$suppressor $\mathrm{T}$ cells (Ts) that are not FoxP3 ${ }^{+}$regulatory $\mathrm{T}$ cells (Treg) [4].

The Ts cells produce and release suppressive, Ag-specific extracellular vesicles (EVs), namely exosome-like nanovesicles [4], that deliver inhibitory miRNA-150. Exosome-targeted antigen-presenting cells (APC), in turn, suppressed the CS effector T cells [4,6]. Exosome-mediated suppression was unequivocally confirmed by an in vivo experiment, showing that systemic administration of these exosomes to actively sensitized hosts at the peak of the hapten-specific effector T cell-mediated CS strongly reduced subsequent immune skin swelling responses measured for over four days [4].

The Ag-specificity of this Ts cell-derived exosome-mediated suppression is due to a surface coating with antibody $(\mathrm{Ab})$ free light chains (FLC) provided by B1a cells that also were activated during tolerogenesis [4]. This Ag-specificity of suppressive exosomes was proved in dual Ag crisscross experiments using two non-cross reactive haptens, and also in similar dual crisscross Ag-affinity column chromatography [4].

We showed previously that contact immunization rapidly activates a subpopulation of Ag-specific peritoneal $\mathrm{B} 1 \mathrm{a}$ cells to migrate to the spleen, where they produce specific IgM $\mathrm{Ab}$ and their derived $\mathrm{Ab}$ FLC [7]. By tolerizing $\mu \mathrm{MT}$ and $\mathrm{JH}^{\text {neg/neg }}$ antibody deficient mice, and coating the resulting exosomes with chosen FLC, we demonstrated that the Ag-specific Ab FLC bind to the surface of Ts cell-derived exosomes. This in turn is responsible for the Ag-specificity of the exosome targeting of CS effector cells [8]. Furthermore, the B1a cells also release non-suppressive exosomes, that already express Ag-specific B cell receptor (BCR) and/or surface Ab FLC [9]. Consequently, we have uniquely shown that in vitro association of these Ag-specific B1a cell-derived exosome-like nanovesicles with miRNA-150, but not control miRNAs, also renders them suppressive. Their effect is similar to the exosomes induced in the Ts-cells of Ag-tolerized mice, that endogenously acquired miRNA-150. This was termed "an alternate Ag-specific exosome-mediated suppression pathway" [10].

Results of these prior studies on CS suppression led to the conclusion that in vivo these Ag-specific B1a cell-derived exosomes can associate with exogenous inhibitory non-exosomal miRNA, perhaps carried in vivo by RNA-binding argonaute proteins [4]. Consequently, such miRNA-150-associated exosomes were strongly inhibitory against CS effector cells [4]. Therefore, it seemed that this miRNA likely was acquired from the freely circulating, extracellular pool of non-exosomal RNAs protected from RNases by chaperones like Argonaut proteins [4]. As an in vivo consequence, these B1a cell-derived exosomes seem able to act indirectly by similar Ag-specific binding to surface Ag of APCs, that then inhibit CS-effector T cells via transfer of their acquired inhibitory miRNA-150 [10].

Given the demonstrated initial suppressive exosome targeting of the APC in CS [6], it was postulated that the actual Ag bound by these FLC-coated suppressive exosomes could be hapten chemically conjugated to self-protein-peptides complexed with MHC on the APC surface, but that could not be determined in the hapten CS system. In the current study, we sought to determine if similar suppression mechanisms applied to classical cutaneous delayed-type hypersensitivity (DTH) induced by ovalbumin (OVA) protein Ag. In this case, it was postulated could show that that exosome-coating FLC might bind target OVA Ag peptide determinants complexed with MHC on the APC surface. The most definitive experiments were administering suppressive exosomes systemically to actively immunized mice at the peak of the skin responses and determining effects on elicited DTH over subsequent days [4]. Surprisingly, the resulting long term systemic suppression resulting from oral administration of either the $\mathrm{T}$ or $\mathrm{B}$ cell-derived suppressive exosomes was superior to intravenous (IV) or intraperitoneal (IP) injections. 


\section{Results}

\subsection{Intradermal Immunization with OVA Induces DTH Effector Cells}

Mice were immunized for induction of protein Ag-specific DTH by ID injections of a high dose of OVA $(100 \mu \mathrm{g})$ without an adjuvant. This allowed elicitation of classical late $24 \mathrm{~h}$ DTH responses to ID ear injection (challenge) with a low dose of OVA (10 $\mu$ g) on day four (Protocol, Figure S1A), compared to controls just immunized with PBS and again similarly ear challenged with $10 \mu \mathrm{g}$ OVA (Protocol, Figure S1B). The DTH response consisted of an initial, weakly Ag-specific, early, edematous ear swelling component, peaking at $2 \mathrm{~h}$ after challenge (Figure S1C), shown previously to be due to B1a cell-derived IgM Ab and their derived Ab FLC $[9,11]$. This early component is required for elicitation of the subsequent classical, Ag-specific, late inflammatory phase, that peaks $24 \mathrm{~h}$ after skin challenge (Figure S1D) [7,9,11]. Three OVA ID immunizing doses were used (20, 100, and $500 \mu \mathrm{g})$. For this dose range, the intensity of elicited DTH, measured as $24 \mathrm{~h}$ ear swelling response [12], was similar (Figure S1D, Groups B, C, and D vs. A). Thus, we chose $100 \mu \mathrm{g}$ of OVA in saline as the optimal immunizing dose administered by ID injection into four sites, as previously described [11].

\subsection{Adoptively Transferred DTH-Effector Cells Were Strongly Inhibited by Incubation In Vitro with Ts Cells That Produced Suppressive Exosomes}

Immune tolerance was induced by IV injection on day 0 and 4 of high doses of OVA Ag linked to syngeneic red blood cells (RBC), followed by OVA ID injection on days 8 and 9 (Protocol, Figure S2A). As tolerogen, OVA was coupled to syngeneic RBC in the presence of either Chromium $\mathrm{Cl}\left(\mathrm{Cr}^{3+}\right)$ or EDC (Figure S2B, 53\% suppression), and EDC was chosen as the optimal coupling agent.

Inhibition of DTH by the tolerogenic procedure was found to be due to generation of Ts cells. One way to show this was by adoptive transfer of DTH effector cells harvested from the ID optimally immunized mice that often were employed as a positive response for testing of Ts cell suppressive exosome activity (Protocol, Figure S2C and Figure S2D, left half). Their suppressor activity was determined by in vitro combining and briefly incubating the Ts cells, or their derived exosomes, with the DTH-effector cells just before the adoptive transfer. Suppression was assayed by inhibition of the co-adoptively transferred OVA DTH-effector cells. This was quantitated by measurement of elicited ear swelling activity of the DTH-effector cells in naive recipients that were ear challenged with the low dose of OVA (Protocol, Figure S2D, right half).

2.3. Ts Cell Suppression Was due to Production of Suppressive EVs that by Surface Expression of Tetraspanins Are Common Small Exosome EVs, and Uniquely also Co-Express Surface Ab FLC

The Ts cells were collected from Ag-tolerized mice on day 11 by harvesting and pooling lymph node and spleen cells. These cells were then cultured for $48 \mathrm{~h}$ to yield supernatant containing the suppressive exosomes (Figure 1A). This combination of IV and ID Ag tolerizing injections of OVA generated OVA-specific Ts cells that released OVA-specific suppressive exosomes able to inhibit adoptive transfer of the DTH effector cells (Figure 1A, Group B vs. A, 80\% suppression). Furthermore, we previously showed in hapten-induced CS that the Ts cells from hapten tolerized mice are CD3 ${ }^{+}$ and $\mathrm{CD}^{+}$[4]. Similarly, in the current OVA DTH system, there also was loss of exosome-suppressive activity when either $\mathrm{CD}^{+}$or $\mathrm{CD}^{+}$populations from the mixed lymph node and spleen cells of mice tolerized with IV OVA-RBC, were depleted with specific IgG monoclonal antibodies (mAb) and complement (Figure 1B). 
A

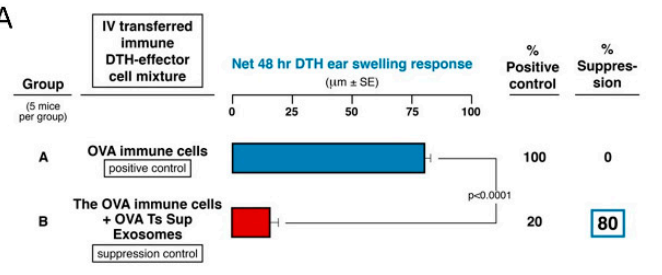

C
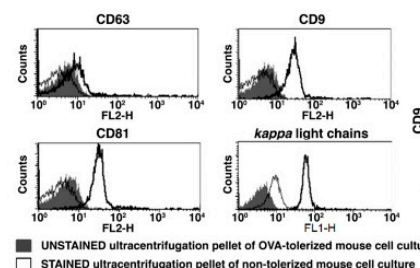

STAINED ultracentritugation pellet of non-tolerized mouse cell culture
$\square$ STAINED ultracentrifugation pellet of OVA-tolerized mouse cell culture

E

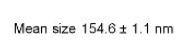

Concentration $2.35 \times 10^{12}$ particles $/ \mathrm{mL}$

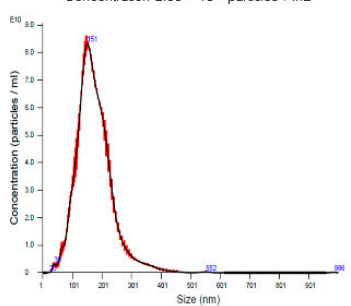

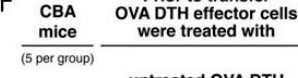

A

B

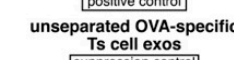

F CBA OVA Prior to transfer

suppression control

anti-CD9 column
flow through fractions

anti-CD9 column
a coliti

anti-CD9 column
ef Ovate fractions
of

B

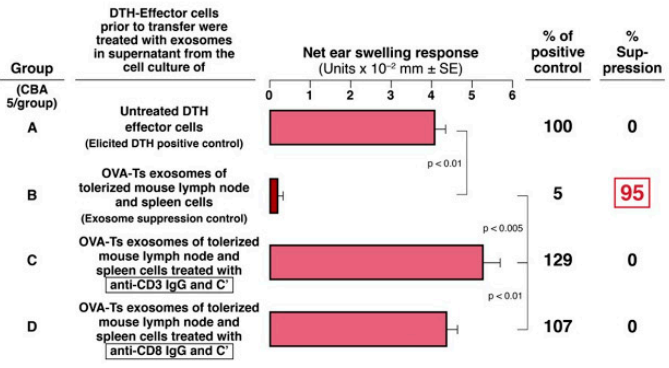

D
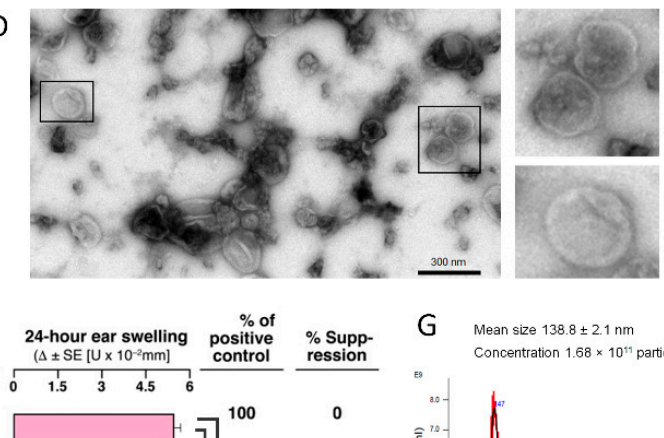

G Mean size $138.8 \pm 2.1 \mathrm{~nm}$ Concentration $1.68 \times 10 " 1$ particles $/ \mathrm{mL}$

0

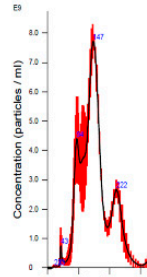

Figure 1. OVA Ag-specific Ts cell-derived, $\mathrm{CD}^{+}$exosomes inhibit adoptive transfer of $\mathrm{T}$ cell mediated DTH. (A) OVA Ag-specific suppressor T cell-derived exosomes inhibit OVA-immune DTH effector cells (Group B, 80\% suppression) undergoing adoptive transfer of DTH (Group A, immune response control). (B) Lymph node and spleen cells of Ag-tolerized mice failed to produce suppressive exosomes when depleted of $\mathrm{CD}^{+}$(Group C) and $\mathrm{CD}^{+}$(Group D) cell populations vs. their exosome suppression control (Group B, 95\% suppression). (C) Flow cytometry showing that OVA-specific Ts cell-derived exosomes express CD9, CD63 (weakest expression), and CD81 tetraspanins, as well as antibody kappa light chains (left and center), and simultaneously co-express CD9 and antibody light chains (right). (D) OVA-specific suppressive exosomes were analyzed with transmission electron microscopy, that showed the presence of nanovesicles with bilamellar membranes. (E) Nanoparticle tracking analysis of OVA-specific Ts cell-derived exosomes to estimate their size and concentration. (F) OVA-specific suppressive exosomes were separated onto an anti-CD9-affinity chromatography column. The resulting anti-CD9 binding and non-binding exosome fractions were then used to treat OVA DTH effector cells prior to their adoptive transfer into naive recipients that $24 \mathrm{~h}$ later were challenged with OVA. The elicited DTH ear swelling responses were measured $24 \mathrm{~h}$ later with an engineer's micrometer, showing that the full suppressive activity of the Ts cell-derived exosomes was in the anti-CD9 binding and eluted fraction (about 10\% of the total) and there was no suppressive activity in the non-binding flow through fraction (Group D vs. C, 71\% suppression vs. 0\% suppression). (G) Nanoparticle tracking analysis of OVA-specific Ts cell-derived exosomes present in the eluate fraction resulting from separation onto an anti-CD9 affinity chromatography column, to estimate their size and concentration. Results of in vivo assays are shown as delta \pm standard error (SE), one-way ANOVA with post hoc RIR Tukey test. $n=5$ mice in each group or three samples in each experimental repetition.

In addition to biological activity, the descriptive characteristics and properties-like phenotype of the assayed OVA Ag-specific suppressive exosomes-resembled the hapten-specific exosome-like nanovesicles isolated from mice tolerized to hapten and also were produced by $\mathrm{CD}^{+}$and $\mathrm{CD}^{+} \mathrm{T}$ cells [4]. OVA-specific exosomes highly expressed CD9 and CD81 tetraspanins with significantly lower expression of CD63 (Figure 1C). Noteworthy for the current OVA system, all of the exosomes 
expressing CD9 tetraspanin also co-expressed surface Ig FLC (Figure 1C, bottom center and right), but here were obvious high (about 10\%) and low expressing (about $90 \%$ ) EV and even exosomes of non-immune animals were slightly positive for the Ig FLC. In addition, transmission electron microscopy revealed the presence of vesicles with billamelar membrane (Figure 1D), characterized by average size around $150 \mathrm{~nm}$, as determined by nanoparticle tracking analysis (Figure 1E). Importantly, these Ts cell-derived exosomes were determined to be biologically active by isolation and then testing for suppressive function of the subpopulation eluted from anti-CD9-linked affinity columns that was strongly suppressive compared to the flow through fraction that did not bind to the anti-CD9 columns (Figure 1F, Group D vs. C). Nanoparticle tracking analysis of OVA Ts cell exosomes eluted from the anti-CD9 affinity column showed the presence of small EV in the column eluate (Figure 1G). Thus, special phenotypic characteristics of small EVs, most likely exosomes, were surely linked to their function. The linkage of phenotype and function is not often tested elsewhere. In addition, when OVA-specific Ts cell-derived exosomes were separated on OVA-linked affinity column, they also strongly suppressed adoptively transferred DTH response (Figure 2A).

In summary, all of these findings concerning phenotypic and descriptive properties of the OVA Ts exosome EV, fit with the recent most thorough description of small EVs of endosomal origin, i.e., exosomes [13]. We also have linked this phenotype to the suppressive function of EVs by testing of their biological activity after separation on OVA Ag and anti-CD9 affinity columns (Figures $1 \mathrm{~F}$ and 2A). Therefore, we have classified the OVA-specific, Ts cell-derived, functionally active, suppressive nanovesicles as exosomes, a small subtype of the vast family of EVs.

\subsection{In Vivo Testing of Ag-Specificity of the Ts Cell-Derived Exosomes}

Expression of FLC and binding to OVA in Ag-affinity chromatography suggested the Ag-specificity of Ts cell-derived exosome action. By employing of Ts cell-derived exosomes induced by the antigenically non-cross reactive protein keyhole limpet hemocyanin $(\mathrm{KLH})$, we have shown that the exosome suppression is Ag-specific. In this case, KLH-specific exosomes harvested from lymphoid cells of mice identically tolerized to KLH, and similarly IP injected into actively OVA-immunized mice just after the peak of the active 24-h OVA-induced DTH response, were totally inactive (Figure 2B). In contrast, Ts cell-derived exosomes harvested from mice tolerized by IV injection of high doses of OVA-RBC (Figure S2A), Ag-specifically inhibited DTH in mice actively immunized with OVA, when delivered systemically IP just before, and, most importantly, $24 \mathrm{~h}$ after ear challenge with Ag (Figure 3). It thus seems that Ag-specificity of exosome mediated suppression likely resulted from the presence of antibody kappa light chains on the Ts-derived exosome surface that enabled Ag-specific binding to the OVA Ag-linked sepharose in the affinity column (Figures 1C and 2A) [8].

\subsection{Role of Antigen-Presenting Macrophages in Exosome-Mediated Suppression}

Ts cell-derived exosomes that had bound to OVA Ag-linked Sepharose columns were found to suppress DTH effector cells (Figure 2A), suggesting that APCs may be targeted by these exosomes. In fact, previous studies on suppression of hapten-induced CS showed that Ag-presenting macrophages are targeted by the Ts cell-derived exosomes, that in turn inhibited the DTH-effector T cells [6]. Thus, in the hapten Ag system, the Ts cell-derived exosome mediated suppression depended on the presence of macrophages acting as APC for the effector T cells [6]. In the current study, we have similarly observed that depletion of macrophages abolishes the suppression in mice tolerized by IV injection of high doses OVA-RBC (Figure 2C, Group C vs. D). This confirms the crucial role of Ag-presenting macrophages for Ag-specific suppressive exosom targeting also applies to the exosome-mediated suppression of OVA-induced DTH.

This experiment shows further that depletion of macrophages also caused decreased DTH-ear swelling responses in actively OVA DTH immunized mice (Figure 2C, Group C vs. A). Therefore, this additionally demonstrates the important role of macrophages acting as APC for the development of the optimal late effector phase of OVA-induced DTH. Thus, for calculations, considering this 
decreased response in macrophage-depleted actively sensitized hosts as a 100\% DTH response, similar macrophage depletion before the elicitation of DTH in the animals that were OVA Ag-tolerized IV prior to the second step of ID immunization, caused a complete reversal of that suppression (Figure 2C, Group D vs. C). Therefore, these data indicate that the tolerogenesis and, as expected, the ability to suppress active DTH, both depend on Ag-presenting macrophages.
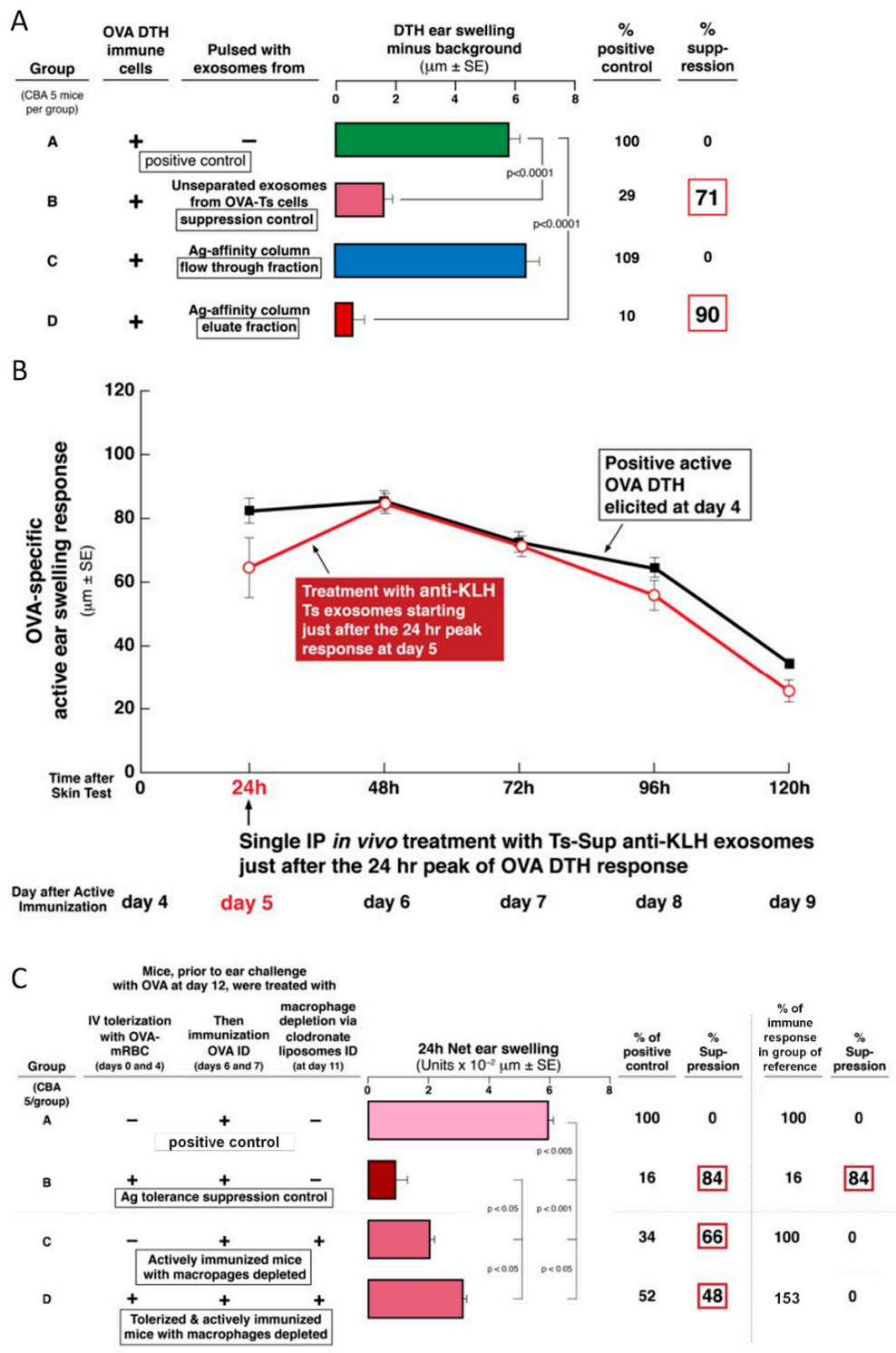

Figure 2. Ag specificity of suppressive exosomes shown by OVA Ag affinity chromatography and criss-cross Ag-testing, and the essential role of antigen-primed macrophages in tolerance induction. (A) OVA-induced DTH is suppressed only by exosomes present in the eluate of OVA Ag-affinity chromatography column separating the exosomes (Group D column eluate vs. Group C column flow through, $90 \%$ suppression vs. $0 \%$ suppression). (B) Ag specificity of suppressive exosome treatment employing analogous anti-KLH protein suppressor T cell exosomes from KLH Ag tolerized donors, that do not inhibit OVA DTH when given IP at the 24-h peak of the OVA-elicited DTH ear swelling response. (C) OVA-induced DTH cannot be suppressed by intravenous tolerization with systemic administration of high doses of OVA-linked syngeneic red blood cells in mice depleted of antigen-presenting macrophages (Group D vs. C). Results are shown as delta \pm standard error (SE), one-way ANOVA with post hoc RIR Tukey test. $n=5$ mice in each group. 
A

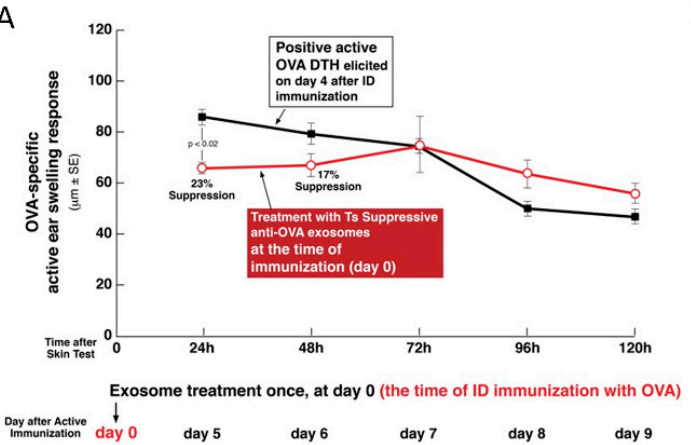

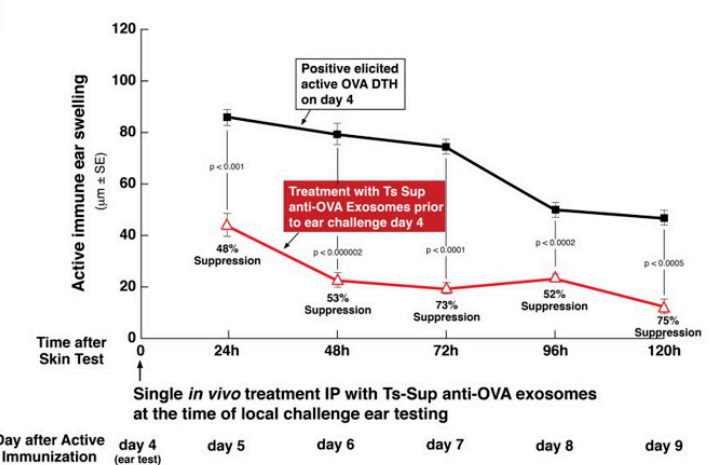
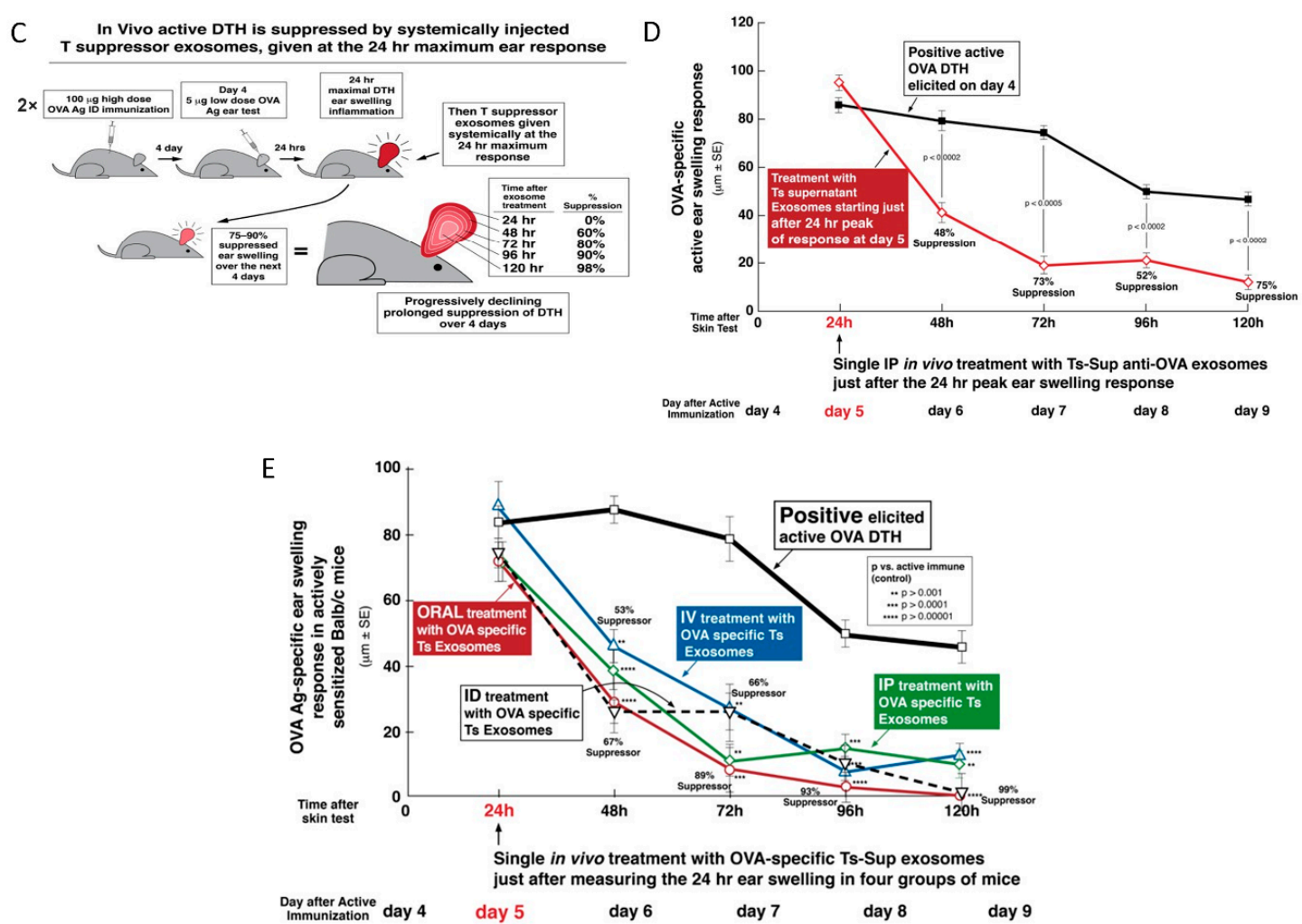

Figure 3. In vivo treatment of active OVA DTH with a systemically administered, single dose of suppressor T cell-derived exosomes, given at various times, and by various routes, including oral and intradermal (ID), with assessment of their Ag-specificity. (A) In vivo treatment of OVA-induced, active DTH with OVA-specific, suppressive exosomes, administered IP at the time of immunization on day 0, were not suppressive of subsequently elicited 24-h DTH ear swelling responses measured over five days. (B) In vivo treatment of OVA-induced, active DTH with OVA-specific, suppressive exosomes, administered IP just before elicitation of the DTH response by ear challenge on day 4, were strongly suppressive (48-75\% suppression over the subsequent five days). (C) Protocol: In vivo treatment of active OVA DTH with systemically administered suppressor T cell exosomes, given just after measurement of the 24-h maximum ear swelling response. (D) In vivo intraperitoneal (IP) treatment of OVA active DTH with OVA-specific suppressor T cell-derived exosomes administered at the 24-h peak of response, were strongly suppressive (48-75\% suppression over the subsequent four days). (E) Comparing intravenous (IV), IP, ID, and oral treatment of actively OVA DTH immunized mice with OVA-specific suppressor T cell-derived exosomes; starting at the 24-h peak of response, and measured over the subsequent four days; all significantly inhibited DTH ear swelling; especially oral treatment (the red line). Results are shown as delta \pm standard error (SE), one-way ANOVA with post hoc RIR Tukey test. $n=5$ mice in each group. 


\subsection{OVA-Specific Ts Cell-Derived Suppressive Exosomes Can Strongly Inhibit Active OVA-Induced DTH In Vivo}

Besides demonstrating the suppression of the adoptively transferred DTH effector cells mixed in vitro with Ts cells or their exosomes, we conducted clinically oriented in vivo experiments. For this purpose, we injected the exosomes derived from the OVA tolerized Ts cells directly into mice with active OVA-induced DTH. When systemically administered into mice via the IP route at the time of immunization, the exosomes were only weakly and briefly inhibitory (Figure 3A). In contrast, they had far greater suppressive activity when injected IP into actively immunized mice just before elicitation of DTH on day 4 (Figure 3B). Most important were results obtained when systemic IP exosome treatment began just after determining the peaking $24 \mathrm{~h}$ responses (Protocol, Figure 3C). In kinetic testing, we found that the OVA-specific, Ts cell-derived exosomes strongly suppressed subsequent daily continuing DTH responses up to $120 \mathrm{~h}$ (day 4) after IP administration of a single physiological dose (Figure 3D). This experiment showed the clinically applicable in vivo suppressive activity of the OVA-specific Ts cell-derived exosomes.

\subsection{Comparison of IV, IP, ID, and PO Systemic Treatments with OVA Ts Cell-Derived Exosomes, Beginning Just after the 24-Hour Peak of OVA DTH, in Actively Immunized Mice}

In the studies described above, OVA-specific suppressive exosomes administered IP to actively immunized mice significantly suppressed the in vivo manifestations of OVA DTH reactions (Figure 3B,D). This systemic administration of the suppressive exosomes at a single dose by the IP route, had not been compared to any other means of treatment. Therefore, we performed new experiments to test the efficacy of treatment with Ts cell-derived, OVA-specific, suppressive exosomes given by more clinically applicable routes; compared to IP treatment. Thus, these OVA-specific suppressive exosomes again were administered systemically at a single dose judged to be physiological, via different routes at the 24-h peak of response in mice that were actively OVA immunized to elicit DTH.

Administration of these exosomes via IP route again was quite suppressive over the subsequent 4 days (Figure 3E, green line) compared to positive control, i.e., untreated active DTH (Figure 3E, thick black line). Furthermore, administering the exosomes IV also caused prolonged inhibition (Figure 3E, blue line), but overall was slightly less effective compared with the IP route.

Outstandingly, the most efficient suppression was observed after PO administration of the single dose of the inhibitory exosomes (Figure 3E, red line). Finally, and interestingly, when treatment with the suppressive exosomes was by the ID route in the torso, this also caused suppression of the DTH responses (Figure 3E, dashed black line). Note that this was via the same route used for Ag immunization, but at different skin sites that also were distant from DTH elicited in the ears.

\subsection{Non-Suppressive Ts Cell-Derived Exosomes from Tolerized miRNA-150 negheg Mice Are Rendered Suppressive by Association with miRNA-150}

In the similar, previously studied tolerance system of the hapten-specific CS response, it was shown that miRNA-150 was required to be carried into the targeted cells by the suppressive exosomes for inhibitory activity [4]. We tested this point here by using exosomes generated by OVA-tolerized miRNA- $150^{\text {neg/neg }}$ mice. Suppression of DTH did not occur in recipients of wild type (WT) OVA-immune DTH-effector cells pretreated in vitro with Ts cell exosomes from tolerized miRNA-150 ${ }^{\text {neg/neg }}$ mice (Figure 4A, Group C vs. A), compared to the strong inhibition by suppressive exosomes generated from miRNA-150 $0^{\text {pos/pos }}$ wild type donors (Figure 4A, Group B vs. A). This indicated that as in the hapten Ag CS system, DTH suppression caused by tolerization with high doses of Ag generated Ts cell exosomes that were also dependent on their ability to deliver miRNA-150 to targeted cells. 


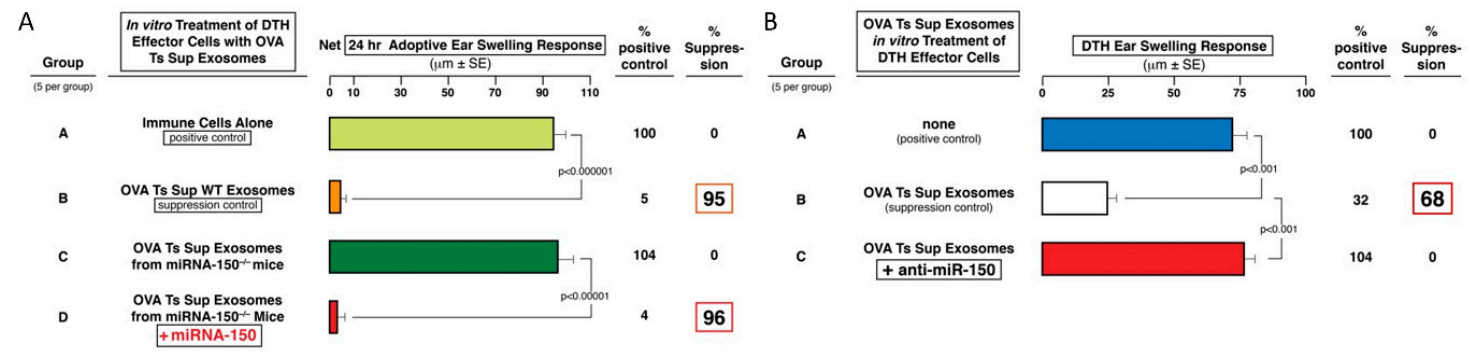

Figure 4. DTH suppression by exosomes from OVA Ag-tolerized mice depends on miRNA-150. (A) Non-suppressive exosomes from OVA Ag-tolerized miRNA-150 ${ }^{\text {neg/neg }}$ mice were restored for ability to suppress 24-h OVA DTH by preliminary in vitro association with miRNA-150 (Group D vs. C). (B) OVA Ag-specific suppressor T cell-derived exosomes that suppress adoptive transfer of OVA DTH, are inhibited by pre-incubation with anti-sense polynucleotide to miRNA-150 (anti-miR-150, Group B vs. C). Results are shown as delta \pm standard error (SE), one-way ANOVA with post hoc RIR Tukey test. $n=5$ mice in each group.

In the CS system, the suppressive exosomes from hapten Ag tolerized mice were additionally activated to be able to associate with a given miRNA in vitro. Accordingly, we tested these non-suppressive exosomes from tolerized miRNA- $150^{\text {neg/neg }}$ mice after incubation in vitro with synthetic miRNA-150. These miRNA-150-treated exosomes from tolerized miRNA-150 ${ }^{\text {neg/neg }}$ mice were converted to be able to suppress the adoptively transferred DTH effector cells, like the exosomes from Ag-tolerized WT miRNA-150 pos/pos mice (Figure 4A, Group D vs. A and C). Thus, the added miRNA-150 seemed to have become associated with the initially non-inhibitory exosomes from miRNA-150 ${ }^{\text {neg/neg }}$ tolerized donors to render them capable of fully suppressing adoptive transfer of OVA-specific DTH-effector cells, to the same extent as suppressive exosomes from Ag-tolerized WT miRNA-150 ${ }^{\text {pos/pos }}$ mice (Figure 4A, Group D vs. B).

As a third experimental confirmation of these findings, OVA Ts cell-derived exosomes from WT mice, presumed to contain inhibitory miRNA-150, were pre-incubated with anti-miR-150 polynucleotide (i.e., a chain with the reverse sequence as miRNA-150), that might hybridize with active miRNA-150. Indeed, this led to strong reversal of the suppression mediated by these anti-miRNA-150 pulsed OVA-induced Ts cell exosomes (Figure 4B, Group C vs. B).

Thus, considering the experiments restoring suppression in exosomes from Ag tolerized miRNA-150 ${ }^{\text {neg/neg }}$ mice, there were two confirmatory results; (i): showing that initially non-suppressive exosomes from tolerized miRNA-150 ${ }^{\text {neg/neg }}$ mice were reconstituted by association with miRNA-150 (Figure 4A), and (ii): showing that DTH-inhibition by natively suppressive Ts cell exosomes from Ag high dose tolerized WT mice was abolished by association of these competent exosomes with anti-miRNA-150 polynucleotide (Figure 4B). Therefore, these results together constituted strong evidence that OVA Ts cell exosomes derived from OVA Ag tolerized mice mediated suppression of DTH due to their content and likely delivery of inhibitory miRNA-150.

2.9. Non-Suppressive OVA Ag-Specific B1a Cell-Derived Exosomes from Ag-Immunized Mice Can Be Rendered Suppressive by Association with miRNA-150

We hypothesized that in this system exosomes need two properties to be suppressive: the $\mathrm{Ag}$ specificity due to surface FLC and delivery of miRNA-150. Accordingly, we tested the ability of non-suppressive, Ag-specific B1a cell-derived exosomes from optimally immunized mice, that were non-suppressive, likely because they contained no miRNA-150, to be rendered suppressive by similar association with miRNA-150 (Protocol, Figure 5A). For this experiment, B1a cell-derived exosomes were harvested from culture supernatants derived from lymph node and spleen cells of mice simply immunized ID with OVA. They were harvested at only 2 days after ID immunization when B1a cells produce Ag-specific IgM antibodies and Ab FLC [9,11]. The B1a cell exosomes in this supernatant 
were hypothesized to likely be OVA Ag-specific due to membrane anti-OVA BCR, and/or a surface coating with anti-OVA Ab FLC, as shown in Figure 5B [8]. We determined that these immune B1a cell-derived exosomes expressed CD9 and CD81 tetraspanins (Figure 5B, left). Additionally, CD9 ${ }^{+}$ vesicles were found to co-express mouse kappa FLC, in contrast to samples from non-immunized animals (Figure 5B, right top vs. bottom). Transmission electron microscopy revealed the presence of bilamellar membranous vesicles in the pellet of ultracentrifuged supernatant of OVA-specific B1 cells (Figure 5C).

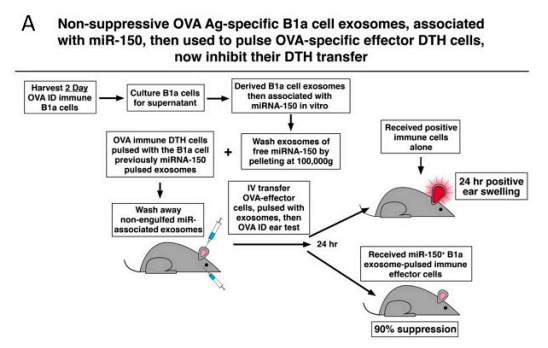

C

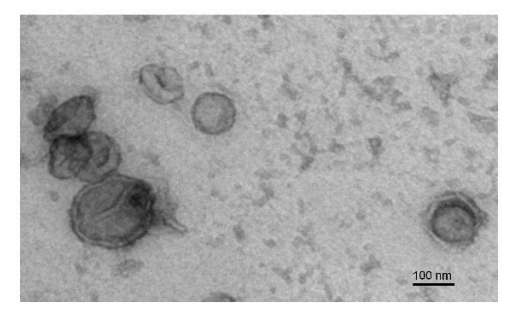

E

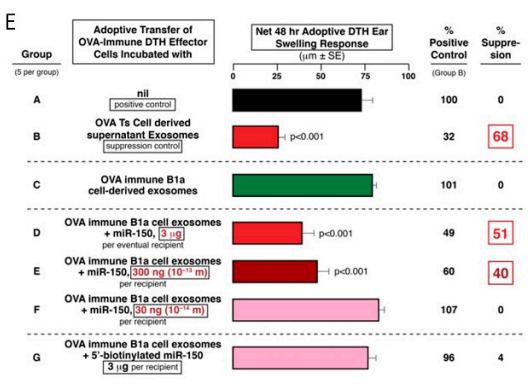

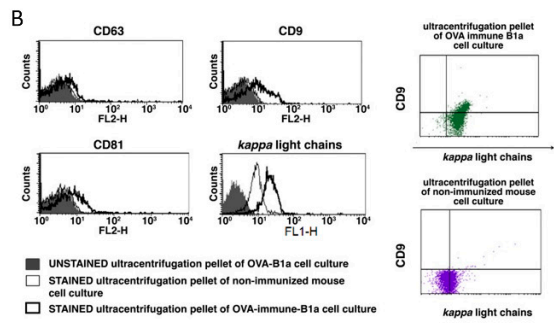
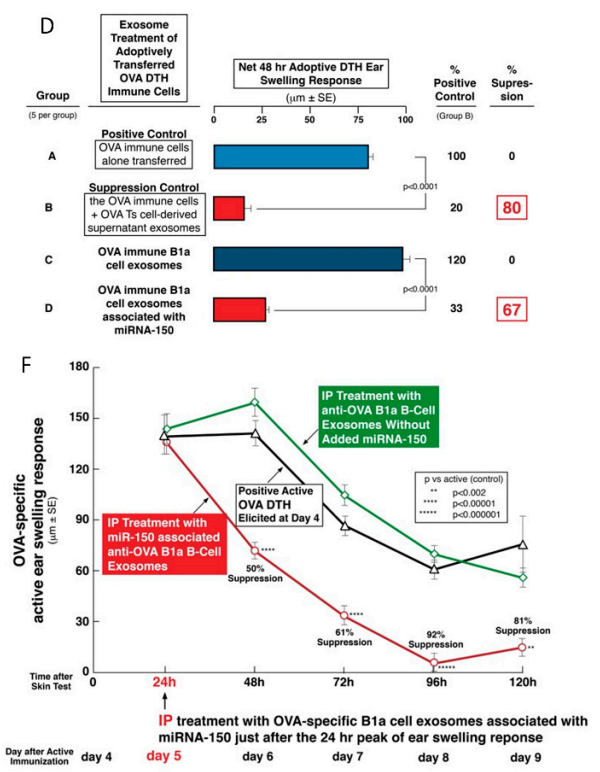

Figure 5. Non-suppressive OVA Ag-specific B1a cell exosomes inhibit adoptively transferred OVA DTH when associated with miRNA-150. (A) Experimental protocol. (B) OVA-specific B1a cell-derived exosomes were cytometrically analyzed for expression of CD9, CD63, and CD81 as general markers of small exosomes, after coupling onto beads (left and center). Furthermore, they were analyzed and found positive for co-expression of CD9 and antibody kappa free light chains (FLC, center, and upper right), while some in the pellet from ultracentrifuged culture supernatant from normal lymphoid cells expressed Ab FLC, but did not co-express CD9 (right lower). (C) B1a cell-derived exosomes were analyzed with transmission electron microscope, showing the presence of bilamellar vesicles. (D) Non-suppressive OVA Ag-specific B1a cell-derived exosomes become suppressive of OVA DTH adoptive transfer when in vitro associated with miRNA-150 (Group C vs. D). (E) A dose response experiment shows that non-suppressive OVA Ag-specific B1a cell-derived exosomes are rendered suppressive of DTH effector cell adoptive transfer by their association in vitro with low doses of miRNA-150. (F) OVA Ag-specific B1a cell-derived exosomes associated in vitro with inhibitory miRNA-150 are able to suppress active OVA DTH when injected intraperitoneally (IP) at the 24-h peak of ear swelling response, in contrast to similar exosomes not associated with miRNA-150 (red line vs. green line, 50-92\% suppression over the subsequent four days), and compared to no treatment of this active DTH (the thick black line). Results of in vivo assays are shown as delta \pm standard error (SE), one-way ANOVA with post hoc RIR Tukey test. $n=5$ mice in each group or three samples. 
As expected, these exosomes derived from optimally immunized, but non-tolerized donors were non-suppressive, likely because they did not naturally contain endogenously generated miRNA-150 since they were not from tolerized mice (Figure 5D, Group C vs. B). In contrast, when these B1a cell-derived, Ag-specific exosomes were in vitro associated with miRNA-150, they became suppressive (Figure 5D, Group D vs. C).

In summary, these data of the OVA protein DTH system confirmed that Ag-specific, suppressive exosomes could be actually derived either from $\mathrm{CD}^{+} \mathrm{Ts}$ cells, then they natively contain miRNA-150 and express surface Ag-specific FLC donated by neighboring activated B1a cells (Figure 1A, Group B), or, alternatively, by immune B1a cells, then they natively express Ag-specific FLC and further were associated with miRNA-150 (Figure 5D, Group D).

\subsection{Dose Response of miRNA-150 Association with Immune B1a Cell-Derived Exosomes}

This type of miRNA association was new, and thus required exploration of physiological relevance by dose-response experimentation. In the CS system, this was shown to be mediated by unusually effective, very low doses of B1a cell exosome-associating miRNA-150 [10]. Accordingly, we determined the least dose of miRNA-150 required for switching OVA-specific B1a cell exosomes to suppressive function in vivo. Use of decreasing serial dilutions of miRNA-150 added to exosomes from B1a cells from early two day OVA immunized mice showed that as little as $300 \mathrm{ng}$ or $10^{-13}$ moles was the limiting dose of miRNA-150 in this system. This amount was sufficient to associate with B1a cell exosomes to mediate highly significant suppression of adoptively transferred OVA DTH mediating immune cells (Figure 5E, Group E vs. C).

An additional feature of this experiment was an attempt to chemically employ $5^{\prime}$-biotinylated miRNA-150 for eventual testing of function of this labeled polynucleotide in suppressing the adoptive transfer of DTH. Such a construct would be useful for detection, quantitation, and kinetic studies of the miRNA-150 carrying suppressive B1a cell-derived exosomes. However, attempted association of the immune activated B1a cell-derived, OVA Ag-specific exosomes with biotinylated miRNA-150 — even at the highest dose of $3 \mu \mathrm{g}$-was not suppressive of OVA-specific effector cells in adoptive transfer of DTH (Figure 5E, Group G vs. C). This suggested that the native miRNA-150 (or perhaps just its native $5^{\prime}$ end sequence) was required for association with exosomes and/or eventual inhibition of the mRNA targeted by miRNA-150. Therefore, this group served as an excellent miRNA control.

Overall, these studies confirmed the ability of miRNA-150 to associate with OVA Ag-specific immune B1a cell-derived exosomes, as we found previously with this type of exosomes also from early immune, but hapten-Ag-specific B1a cells [10]. The limiting dose here was much greater than in the hapten system, and biotinylating the $5^{\prime}$ end of miRNA-150 prevented association or function in targeted cells.

\subsection{Prolonged In Vivo Suppression by Systemic Treatment of Active OVA DTH Responses with B1a Cell-Derived Exosomes Associated with miRNA-150}

Important in any therapy, is attaining a significant duration of the effect; especially in clinical translation to patients. We showed above strong and prolonged in vivo suppression of existing OVA DTH over four days in actively immunized mice treated with a single dose of Ts cell-derived exosomes administered by multiple routes (Figure 3E). Accordingly, we performed a further kinetic study in the OVA DTH system, but now employing the newly described B1a cell-derived exosomes, rendered suppressive by in vitro association with inhibitory miRNA-150 (Figure 5D,E). We found that systemic, single physiological-dose IP treatment begun at the 24-h peak of response with miRNA-150 associated OVA Ag-specific B1a cell exosomes had similar profound and prolonged OVA DTH suppressive effects over the subsequent four days (Figure 5F, red line, 50-92\% suppression), when compared to identical but miRNA-150 unassociated B1a cell-derived exosomes (Figure 5F, green line), and to hosts with elicited active DTH that had no treatment (Figure 5F, black line). Therefore, OVA DTH suppression 
like that mediated by $\mathrm{T}$ cell-derived exosomes from Ag tolerized mice could be constructed from these Ag-specific and miRNA-150 loaded B cell-derived exosomes.

\subsection{Comparing the Binding of Four Different Anti-OVA $m A b$ and Their Derived Light and Heavy Chains,} as well as Polyclonal Anti-OVA FLC to Various OVA Preparations

An important question about DTH inhibition by Ag-specific, suppressive exosomes is the mechanism of suppression; including the mechanism of the Ag-specificity due to a coating with $\mathrm{Ab}$ FLC [8]. To examine this, we employed a set of four different anti-OVA IgG monoclonal antibodies, where each was rendered into its Ab heavy and Ab FLC. We compared the ability of these constituent chains to whole IgG in dose response binding to native OVA Ag, adhering to wells of enzyme-linked immunosorbent assay (ELISA) plates and serially diluted from 2.5 to $0.078 \mu \mathrm{g}$ per ml (Figure 6A).
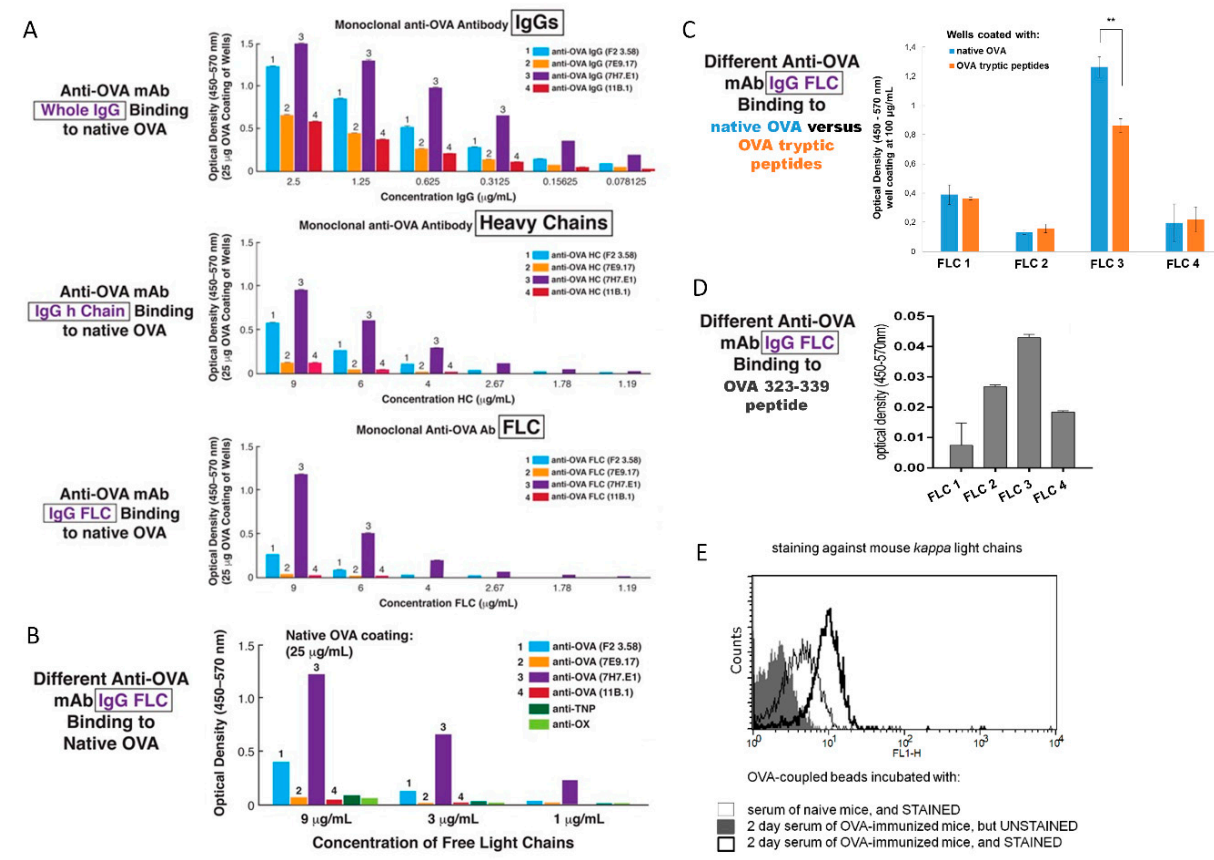

Figure 6. ELISA assays to assess the ability of four different monoclonal anti-OVA Ab-derived free light chains (FLC) to bind to native OVA, OVA tryptic peptides, and OVA 323-339 peptide, as well as flow cytometry analysis of anti-OVA Ab FLC in 2-day immune serum. (A) Binding to native OVA by serial dilutions of four different monoclonal anti-OVA Ab-derived FLC and Ab heavy chains, vs. The whole IgGs, shows significant binding with a particular $\mathrm{mAb}$ and similar strength with a given $\mathrm{mAb}$ and its derived heavy and light chains. (B) Binding of various monoclonal anti-OVA Ab FLC to native OVA compared to binding of control anti-OX and anti-TNP hapten-specific mAb shows the Ag specificity of the anti-OVA Ab FLC binding. (C) Comparison of binding of four monoclonal anti-OVA Ab-derived FLC to either native OVA or OVA tryptic peptides, showing a difference only in the case of FLC 3. The two-tailed Student $\mathrm{t}$ test, ${ }^{* *} p<0.01$. (D) Binding of four monoclonal anti-OVA Ab-derived FLC to OVA 323-339 antigenic determinant. (E) The presence of OVA Ag-specific Ab FLC in 2-day serum of OVA-immunized mice (thick black line) was confirmed by flow cytometry, as compared to serum of control non-immunized mice (thin black line). $n=3$ wells or samples in each experimental repetition.

Over the dilution range employed, binding to native OVA adsorbed to plastic ELISA wells, occurred with the whole IgGs as well as the separate Ab heavy and light chains. The anti-OVA mAb were numbered 1, 2, 3 and 4, and a rank order of binding was determined. Binding of the isolated heavy and light chains to native OVA Ag was in the same rank order for a given anti-OVA whole monoclonal $\mathrm{IgG}$, and just differed in strength of OVA-binding comparing the four $\mathrm{mAb}$ (Figure 6A). For each $\mathrm{mAb}$, 
binding was best with whole IgG and next the heavy chains and least the FLC (Figure 6A), but in the same rank order for each $\mathrm{mAb}$.

Another related ELISA experiment showed that the binding to native OVA by Ab FLC was shown to be could be Ag-specific, when compared to two different anti-hapten mAb FLC; i.e., anti-oxazolone and anti-TNP FLC (Figure 6B). These various anti-hapten mAb FLC were shown previously to bind to and convert non-suppressive exosomes derived by Ts cells from hapten $\mathrm{Ag}$ tolerized pan Ab deficient $\mathrm{JH}^{\text {neg/neg }}$ mice to suppressive function, in adoptive transfer of a CS-effector cell mixture [4].

In another ELISA assay we have compared the four $\mathrm{mAb}$ IgG-derived FLC for their binding to native OVA and OVA tryptic peptides. FLC 1, 2, and 4 bound with a similar strength to both OVA preparations, while binding of FLC 3 to OVA tryptic peptides was weaker than to native OVA (Figure 6C). Furthermore, all assayed FLC were shown to bind to OVA 323-339 antigenic determinant but, however, with a very low efficacy (Figure 6D).

As mentioned above, Ag-activated B1a cells provide FLC for coating of Ts cell-derived exosomes (Figure 1C). Thus, we speculated that these B1a cell-derived FLC could be found in serum collected from mice ID immunized with OVA 2 days earlier. Prior studies in the CS system and in a model of early resistance to pneumococcal pneumonia indicated that such sera contain polyclonal anti-hapten $\operatorname{IgM~Ab}$, and also Ab FLC with diverse Ag-specificities due to germ line V-region mutated DNA sequences in a subpopulation of these ordinarily germ line expressing early B1a cells [14-16]. Thus, to evaluate this idea, latex beads coated with native OVA antigen were incubated with OVA immune sera, washed, stained against mouse kappa light chains, and subjected to flow cytometric analysis, that revealed the presence of Ab FLC, that bound to OVA-coated beads, in tested sera (Figure 6E). As expected, the amount of detected anti-OVA FLC was much greater in sera of OVA-immunized mice, when compared to naive mouse sera (Figure 6E).

\subsection{Testing the Anti-OVA mAb FLC That Coat Ts Cell-Derived Exosomes Reveals Their Ability to Bind to OVA Antigenic Determinants}

To assess the involvement of Ab FLC in suppression of DTH by Ts cell-derived exosomes in vivo, the same amounts of anti-OVA FLC 1, 2, 3, and 4 were used to coat identical aliquots of Ts cell-derived exosomes from OVA Ag tolerized JH $\mathrm{H}^{\text {neg/neg }}$ mice (Figure 7A, protocol). Because of their genetic defect in $\mathrm{Ab}$ production, the $\mathrm{JH}^{\text {neg/neg }}$ mice do not produce native $\mathrm{Ab}$ FLC and, therefore, their derived exosomes are not suppressive on their own $[4,8,10]$. Thus, we tested the relative ability of the four $\mathrm{mAb}$-derived FLC to restore suppressive action of exosomes, when used to coat the exosomes generated by Ts cells from OVA Ag-tolerized $\mathrm{JH}^{\text {neg/neg }}$ mice. We found that the $\mathrm{JH}^{\text {neg/neg }}$ mouse $\mathrm{Ts}$ cell exosomes coated with FLC 2, 3, and 4 mediated significant suppression of adoptively transferred DTH effector cells (Figure 7B). Simultaneously, we performed an ELISA-based assay to compare the binding of $\mathrm{JH}^{\text {neg/neg }}$ mouse Ts cell-derived exosomes coated with four mAb-derived FLC to native OVA and OVA tryptic peptides (Protocol, Figure 7C, left), that was found similar in the case of FLC 1, 2, and 4 when tested as freely dispersed in assay buffer (Figure 6C). This assay showed a significantly greater amount of $\mathrm{JH}^{\text {neg/neg }}$ mouse Ts cell exosomes that bound to OVA tryptic peptides in comparison with binding to native OVA, when these exosomes were coated with FLC 1, 2, and 4, but not with FLC 3 (Figure 7C), suggesting that some FLC bind OVA tryptic peptides stronger when coated onto exosomes. Therefore, these observations led us to hypothesize that the ability of Ab light chains to allow exosomes to Ag-specifically suppress DTH effector cells depends mostly on the total avidity of Ag-binding by multiples of the FLC that coat suppressive exosomes, that combines their individual affinities. To test this hypothesis, we have applied FLC 2 and 3, that differed in their binding capability (Figures 6C and $7 \mathrm{C}$ ) and suppressive activity (Figure 7B), as well as 2-day immune serum from OVA-immunized mice, onto an affinity chromatography column filled with sepharose conjugated with OVA tryptic peptides. The yielded column eluates containing FLC that had strongly bound to OVA tryptic peptides, were then used to coat $\mathrm{JH}^{\text {neg/neg }}$ mouse Ts cell-derived exosomes that were incubated with DTH effector cells prior to their adoptive transfer. We observed that coating of $\mathrm{JH} \mathrm{H}^{\text {neg/neg }}$ mouse Ts cell exosomes with 
OVA tryptic peptide-binding FLC 2 and 3, and OVA-immune serum FLC, led to significant suppression of DTH response (Figure 7D). This confirmed that the ability of FLC to bind the Ag peptides indeed determines their suppressive activity when coating the Ts cell exosomes.

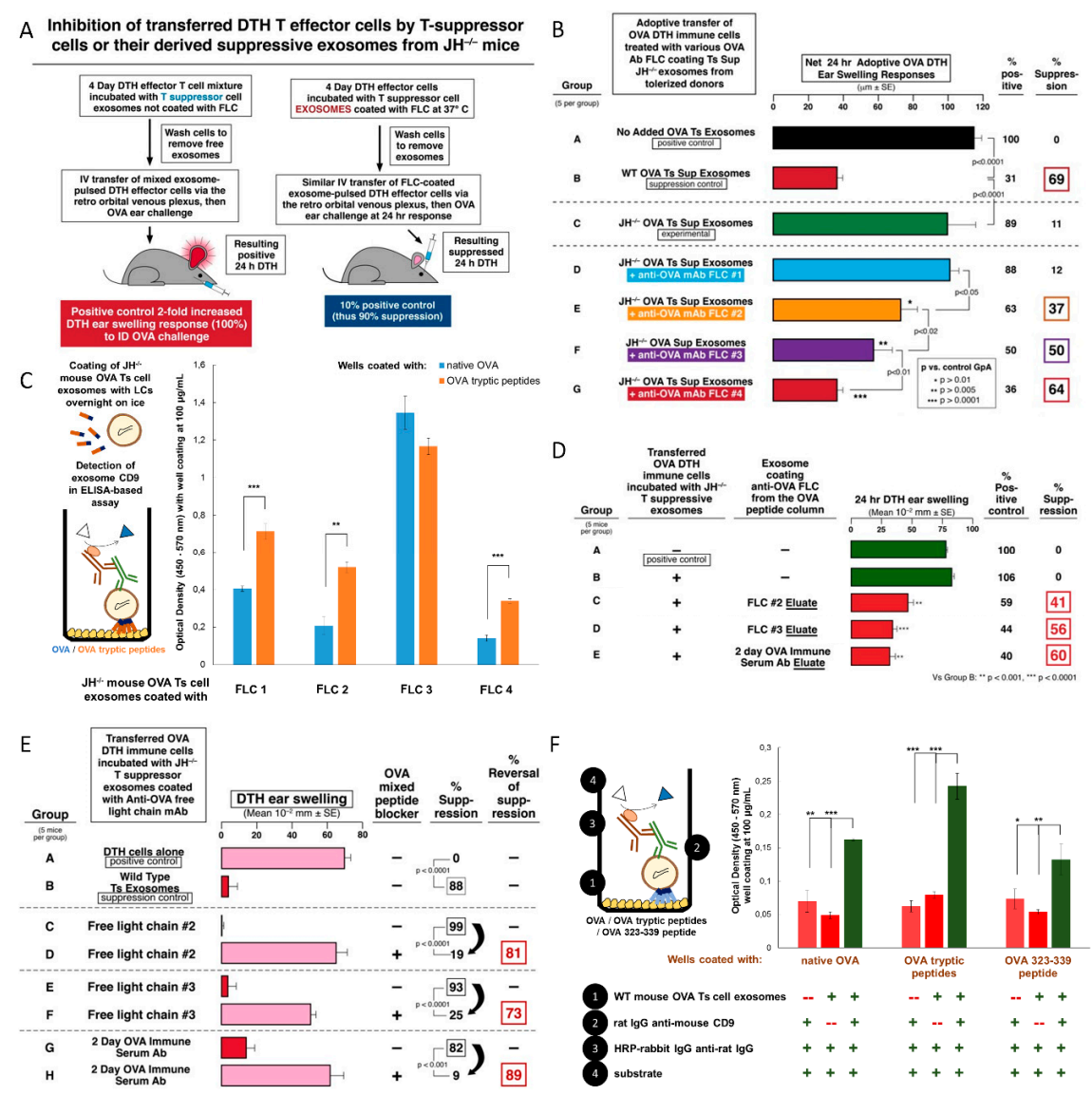

Figure 7. Inhibition of transferred OVA DTH effector cells that were pulsed with exosomes from Ag-tolerized $\mathrm{JH}^{\text {neg/neg }}$ mice that were in vitro coated with the four different anti-OVA Ab FLC. (A) Protocol: Inhibition of adoptively transferred OVA DTH effector cells when preliminarily pulsed with exosomes from Ag-tolerized WT donors, compared to those from similarly Ag tolerized JHeg/neg mice, that in some cases were additionally coated in vitro with the four different anti-OVA mAb FLC. (B) Adoptive transfer of OVA DTH effector cells pulsed in vitro with OVA-specific Ts cell-derived exosomes from Ag-tolerized $\mathrm{JH}^{\text {neg/neg }}$ mice, reconstituted for suppression by in vitro coating with the four different anti-OVA mAb FLC. (C) ELISA-based assay (scheme-left) to evaluate the binding of $\mathrm{JH}^{\text {neg/neg }}$ mouse Ts cell-derived exosomes coated with four different monoclonal anti-OVA Ab FLC to either native OVA or OVA tryptic peptides, showing the stronger binding to OVA tryptic peptides in the case of FLC 1, 2, and 4. (D) Successful reconstitution of suppression by coating of non-suppressive $\mathrm{T}$ cell exosomes derived from OVA Ag-tolerized $\mathrm{JH}^{\text {neg/neg }}$ mice with anti-OVA mAb FLC numbers 2 and 3 or 2-day immune serum FLC eluted from OVA tryptic peptide-linked affinity column. (E) Use of OVA tryptic peptides to potentially block anti-OVA mAb FLC that coat Ts cell-derived suppressive exosomes. The OVA peptides block anti-OVA mAb FLC and FLC from OVA-immune serum that coated Ts cell-derived suppressive exosomes from Ag-tolerized $\mathrm{JH}^{\text {neg/neg }}$ mice, on adoptive transfer of DTH, mediated by a mixture of APCs and OVA-specific DTH effector T cells. (F) ELISA-based assay (scheme-left) to evaluate the binding of wild type mouse Ts cell-derived suppressive exosomes to either native OVA, OVA tryptic peptides or OVA 323-339 antigenic determinant, showing that exosomes originally coated with anti-OVA FLC can bind to all assayed OVA preparations. Results of in vivo assays are shown as delta \pm standard error (SE, $n=5$ mice in each group), and of in vitro assays as mean \pm standard deviation (SD, $n=3$ wells in each experimental repetition), one-way ANOVA with post hoc RIR Tukey test or two-tailed Student's $t$-test, ${ }^{*} p<0.05 ;{ }^{* *} p<0.01 ;{ }^{* * *} p<0.001$. 
It has been previously shown that coating of exosomes from Ts cells generated by hig Ag dose-induced tolerance with Ab FLC mediated the Ag-specificity of suppression $[4,6,8]$. According to our overall observations, we therefore proposed that Ab FLC, when coating the suppressive exosomes, bind to antigenic peptide determinants, that can enables Ag-specifica targeting of APCs present in the DTH effector cell mixture. To initially test this hypothesis, we coated $\mathrm{JH}^{\text {neg/neg }}$ mouse $\mathrm{Ts}$ cell-derived exosomes with FLC 2 and 3, and with serum-derived FLC, and then incubated these FLC-coated exosomes with OVA tryptic peptides prior to treating DTH effector cells. Pre-incubation of the FLC-coated exosomes with OVA tryptic peptides blocked their suppressive activity (Figure 7E, groups D vs. C, F vs. E and H vs. G), thereby proving that the interaction of FLC-coated exosomes likely with Ag peptides is required for suppression.

Thus, to finally confirm the ability of FLC-coated exosomes to bind to peptide antigenic determinants, we have compared the binding of wild type C57BL/6 mouse Ts cell exosomes, that are originally coated with Ab FLC (Figure 1C), to native OVA, OVA tryptic peptides, and OVA 323-339 antigenic determinant, in an ELISA-based assay (Protocol, Figure 7F, left). This showed that the highest amount of the suppressive exosomes bound to OVA tryptic peptides, then to native OVA and to OVA 323-339 peptide (Figure 7F). Taking into account that only a part of the OVA-primed B1a cells produce OVA-323-peptide-specific FLC, this observation unequivocally proved that the suppressive exosomes bind to peptide antigenic determinants on the APC due to their coating with Ag-specific FLC, thereby allowing antigen-specific targeting of the APCs expressing surface OVA Ag-peptide complexed with MHC to enable suppression of the DTH response.

\section{Discussion}

\subsection{Ag-Specific Ts Cell-Derived Exosomes Mediate Tolerance Induced by Ag High Dose Systemic Administration}

The current study has contributed greatly to further understanding of our original discovery of Ag-specific immunosuppressive exosomes [4]. These prior findings were from the hapten-specific effector T cell-mediated, in vivo system of cutaneous CS, where the Ag-specific tolerance was shown to be due to exosome-like nanovesicles coated with Ab FLC delivering miRNA-150 [4,8]. The central finding of this unique system was that systemic treatment of mice with such Ag-specific, immune suppressive exosome-like nanovesicles strongly inhibited established CS in actively sensitized hosts, when we systemically administered a single physiological dose of the vesicles at the 24-h peak of the cutaneous immune response. Those inhibitory exosome-like nanovesicles in the CS system were secreted by $\mathrm{CD}^{+}{ }^{+}$Ts cells not expressing the Treg cell marker FoxP3 [4], and targeted Ag-presenting macrophages [6]. After induction of tolerance to hapten in donor mice, their suppressive exosome-like nanovesicles were found in their immune sera, plasma, and in the supernatant of their cultured spleen and lymph node cells [4]. Thus, suppressive exosomes were released and acted systemically to achieve Ag-specific immunological tolerance due to their suppression, and were able to act at local sites of CS elicitation in the ear skin after systemic administration.

This current new study was extended to OVA protein Ag-induced tolerance, that was similarly mediated by Ag-specific nanovesicles, determined to be common small EVs, most likely exosomes, coated with anti-OVA Ab FLC, and also again delivering inhibitory miRNA-150, acting on macrophage APC, likely by binding to their surface expressed OVA peptides in MHC to inhibit their companion peptide-Ag-MHC-specific DTH effector T cells.

\subsection{Development of the OVA Protein Ag-Induced DTH System Regulated by Ag-Specific, Ts Cell-Derived Inhibitory Exosomes Delivering miRNA-150}

Our findings in the hapten-induced CS system were new, unique, unconventional, and a bit controversial. The findings were made in a system of hapten chemical Ag-specificity, and indicated that the exosome-like nanovesicles targeted the APC, that guided the eventual suppression of their companion CS-effector T cells [6]. However, the exact entity likely on the APC surface bound by the 
Ag-specific FLC coating these suppressive exosomes could not be determined in this CS system. This is because hapten immunization and challenge results in hapten binding over the whole APC surface as it becomes chemically covalently linked to diverse host proteins.

The current study was performed in the different, OVA protein Ag-induced DTH system, and allowed expansion of the previous findings by being able to determine the Ag entity targeted on the APC surface. This enabled exosome-mediated transfer of miRNA-150, that in turn activated suppressive function of these APC, that then inhibited companion OVA-specific DTH-effector T cells. Our current new findings indicate that peptides of the OVA Ag, likely in complex with MHC on the APC surface, are very likely bound by Ab FLC coating the surface of these Ts cell-derived suppressive exosomes.

There was a further important property of treatment with the previously studied hapten Ag-specific exosomes, expanded here in the OVA protein Ag DTH system. In CS, in vivo suppression was mediated by physiological doses of the nanovesicle exosomes, that was effective even when a single systemic IP dose of suppressive exosome vesicles was administered at the in vivo maximum $24 \mathrm{~h}$ peak of the cutaneous response and lasted for several days [4]. In the current study, suppression of OVA DTH was achieved by systemic administration of a physiological dose of exosomes from OVA-tolerized mice by the IP, IV, ID, and even the oral route; the latter producing the most powerful inhibition (Figure 3E).

\subsection{Significance of Administrating the Suppressive Exosomes Orally}

A remarkable new finding was that the OVA-specific suppressive exosomes can even be given orally to actively immunized recipients in a single dose, again at the height of the T cell effector response to achieve strong inhibition of elicited DTH. In fact, this produced the strongest effect of all routes examined with prolonged suppression over four days of established DTH at the particular systemic site of the Ag-challenged ear skin (Figure 3E). These findings are very important since in general they resemble the clinical situation of treating a patient with a pre-existing and ongoing immune-mediated reaction. Furthermore, successful and powerful suppressive treatment with exosomes via the oral route-if translated to the clinical situation-is a low impact and high effect treatment modality that obviously would be convenient to patients; especially children.

\subsection{Hapten and Protein Ag-Specific Suppressive Exosomes}

Our prior study was the first description of natural, Ag-specific exosome-like nanovesicles, uniquely composed of components from two different cell types; i.e., $\mathrm{T}$ cells and $\mathrm{B}$ cells. The $\mathrm{T}$ cell-derived component was miRNA-150 contained in exosome-like nanovesicles from hapten immune tolerance-mediating $\mathrm{CD}^{+} \mathrm{CD}^{+}$Ts cells induced by administration of high systemic doses of hapten $\mathrm{Ag}$ [4]. These $\mathrm{CD} 8^{+}$Ts cell-derived exosomes had Ag non-specific, suppressive activity due to their ability to deliver inhibitory miRNA-150 to targeted cells [4]. Furthermore, anti-hapten B1a cells, also activated by the tolerogenic procedure, provided hapten-specific Ab FLC for coating the Ts cell-derived exosome-like nanovesicles to render them Ag-specificcally suppressive of elicited CS responses $[4,8]$.

In the current study, OVA Ag-induced high dose tolerance was also found to be mediated by $\mathrm{CD}^{+} \mathrm{CD}^{+}$cells producing Ag-specific, suppressive exosomes, similarly coated with Ab FLC and particularly transferring miRNA-150 cargo. Furthermore, the OVA-Ag-specific suppressive exosomes similarly targeted the APC that were companions of the finally suppressed OVA-specific DTH effector $\mathrm{T}$ cells (Figure 2C).

Other EV-mediated mechanisms of immune suppression have already been described and claimed to have Ag-specific activity. However, this has often been tested only in one-way Ag-activity system by simple comparison to challenge with another Ag or just media, or testing non-immune hosts with the involved Ag, as controls. Thus, the mechanisms in these studies should instead be considered only Ag-dependent [17-28]. Furthermore, the Ag-specificity of the function of other suppressive exosomes was not established in the important and meticulous study of RNAs involved in the suppression of 
Th1 cells by classical FoxP3 ${ }^{+}$Treg cells [25], and in another study on immunopathogenesis mediated by Treg cell-derived EVs [29].

In great contrast, our prior studies on CS suppression definitively established the strict hapten Ag-specificity of exosomes by dual reciprocal testing $[4,8,10]$. In the current DTH studies, we have also reciprocally tested the Ag-specificity of exosome-mediated tolerance to a pair of unrelated protein Ag; i.e., OVA and KLH. Accordingly, OVA-specific suppressive exosomes strongly inhibited effector DTH responses to OVA protein Ag in actively immunized mice. Reciprocally, KLH-specific suppressive exosomes failed to suppress OVA-induced DTH (Figures 3D and 2B). This proved that protein-Ag-specific suppressive exosomes acted in a strictly Ag-specific manner.

\subsection{Protein Ag-Specific, B1a Cell-Derived, Non-Suppressive Exosomes Can Be Rendered Suppressive by In Vitro Association with miRNA-150}

A very important aspect of the hapten CS-inhibiting, Ts-cell-derived exosomes was carriage and then delivery of miRNA-150 to targeted cells, that alone compared to controls inhibited Ag presentation by these acceptor macrophages [6]. Importantly, we confirmed this exact scenario in OVA protein Ag high dose tolerance induced by exosomes mediating suppression of OVA DTH, that were effective only in the presence of Ag-presenting macrophages. In both the CS and DTH systems, Ag-specific targeting of exosomes derived from $\mathrm{CD} 8^{+} \mathrm{CD}^{+}$Ts cells was mediated by their surface Ab FLC derived from cells other than those that produced the exosomes (i.e., by co-activated B1a cells) [8].

Furthermore, we described another and equivalent complex biological process that was based on the recognition that the essential aspects of the suppressive exosomes in CS and DTH was exosome surface Ag-specificity and delivery of miRNA-150 [4,10]. To construct this with natural components, we employed exosomes derived from B1a cells generated at only two days after immunization ID with OVA alone [11,30]. Although these B1a cell-derived exosomes were OVA-specific due to the surface expression of OVA Ab FLC and/or anti-OVA BCR, they were not suppressive, since they lacked a miRNA-150 cargo, because the donors were not Ag-tolerized. Thus, of crucial significance-as in CS suppression [10] —we found that in vitro association of these B1a cell-derived, OVA Ag-specific exosomes with miRNA-150 alone rendered them suppressive of the OVA-specific effector T cells by acting on their APC. Furthermore, these miRNA-150-associated, anti-OVA B1a cell-derived exosomes were strongly suppressive over subsequent days, when injected systemically at the 24-h peak of the OVA-specific DTH response (Figure 5F), and this was comparable to suppression mediated by the OVA-specific Ts cell-derived exosomes (Figure 3D,E) [10]. In summary, we hold that achieving this suppression by simply combining the naturally produced B1a cell-derived exosomes from optimally immunized donors that express surface $\mathrm{Ab}$ - together with selection of carried miRNA-150 cargo-is the strongest proof of principal definitively verifying the ideas concerning the biologically functional Ag-specific suppressive exosomes. This was the main focus of our ongoing studies.

3.6. Dose Response Testing to Determine the Limiting Dose of Associating miRNA-150 to Mediate Suppression of OVA DTH by B1a Cell Exosomes

The in vitro procedure of associating miRNA-150 with anti-OVA B1a cell-derived exosomes also allowed for testing the limiting dose of associating miRNA-150 able to mediate suppression of OVA-induced DTH. Such a rarely done dose response experiment showed that the minute dose of only $300 \mathrm{ng}$ or $1 \times 10^{-13}$ moles of miRNA-150 sufficed for suppression of an OVA-specific DTH effector cell mixture adoptively transferring DTH (Figure 5E). This compares to the very unusual, ultra-low dose of $50 \times 10^{-15}$ moles, or 50 femtomoles of miRNA-150, associating with B1a cell-derived hapten Ag-specific exosomes for suppression of CS adoptive cell transfer [10]. However, there is as yet no method allowing accurate determination of the percentage of miRNA-150 taken up by these exosomes and further exosome uptake by the targeted cells. Therefore, in actuality, much less miRNA-150 may be exosome-transferred in both cases to induce the biological effects. 
The apparent difference in limiting dose of miRNA-150 in CS and DTH may be due to the distinctive aspects of the involved mechanisms. In CS, the targeted cells are exposed to and linked with many molecules of reactive hapten applied to these macrophage APC, and thus will likely have great amounts of hapten covalently conjugated to multiple entities on their surface beyond those haptens conjugating to self-peptides complexed in MHC. This would allow for great diversity of Ab-linked suppressive exosome binding, uptake, and possible subsequent induction of intracellular mechanisms mediated by transferred miRNA-150. In contrast, in OVA-induced DTH, similar Ab-coated suppressive exosomes seem to just bind the foreign OVA Ag-derived peptides only expressed in complexes with limited numbers of MHC molecules on the APC surface, as the only possible Ag-specific targets for their surface Ab FLC.

\subsection{Confirmation That Ag-Specific Exosomes Mediate miRNA Delivered Suppression in Two Different DTH Systems}

Various findings of Ab-dependent, exosome-mediated suppression in hapten CS, were now repeated in protein Ag-induced DTH. As a first potential treatment scenario, this offered a unique situation of constructing functionally suppressive exosomes derived again from two cell types; i.e., T cells and B cells. Firstly, this has potential clinical significance, since there is the tolerogenic route of inducing Ts cell-derived endogenous miRNA-containing exosomes to be coated by either native or chosen B1a cell-derived, endogenously available Ab FLC.

In a second scenario, aimed at creating suppressive B cell-derived exosomes for treatment, immunization of patients with exogenous Ag or altered self-Ag might induce a B1a cell source of exosomes that are Ag-specific due to either a surface expression of $\mathrm{BCR}$ specific for that immunizing Ag, or via a coating of endogenous Ab FLC. Additionally, two exosome types-i.e., Ts cell- or B1 cell-derived, that could be, respectively, endogenously or in vitro associated with a chosen miRNA, or likely siRNA - would then mediate selected miRNA-dependent Ag-specific alteration of APC function. Indeed, when transferred to totally syngeneic recipients (Figures $3 \mathrm{E}$ and $5 \mathrm{E}$ ), they may induce desired epigenetic alterations in specifically targeted host APC, that bear Ag-peptide surface determinants of the given $\mathrm{Ag}$ to be bound by the Ab FLC or Ab-like BCR on the exosome surface. The in vitro miRNA association process would follow steps in the new alternate pathway for in vivo exosome-mediated transfer of extracellular RNA (exRNA) between cells that we described previously [10]. Clinically, there are other conditions possibly applicable to regulation by the Ag-specific chosen miRNA-delivering exosomes, involving protein Ag DTH-like systems; possibly including protein immune reactivity in asthma, autoimmunity, transplantation, or cancer. Since exosomes seem to be universal nanoparticles of all of life, such natural nano particle constructs would constitute a new simple approach for simultaneous and mutually interacting chosen Ag and gene-specific therapy to curb excessive DTH or related $\mathrm{T}$ cell reactivity in such disease processes.

\subsection{Potential Application of Dual Ag-and Gene-Specific Exosome to Clinical Conditions Like Anti-Cancer Therapies}

Similar combined specific treatment of leukemia and cancers is becoming available in emerging chimeric $\mathrm{T}$ cell antigen receptor (CAR) therapy. This might be delivered instead by exosomes with advantages as cell-free carriers, a far less complicated modality for targeted therapy in cancers and possibly in other diseases [31]. However, current CAR therapy is dependent on a single V-region gene encoded $\mathrm{T}$ cell reactivity to a single given peptide-Ag/MHC determinant. Unfortunately, this fixed property is subjected to the well-known ability of cancers to evolve resistance to a given therapy, in this case away from the vulnerable single tumor expressed monoclonal $\mathrm{T}$ cell receptor for Ag-peptide/MHC [32-34]. This compares to the possibility of using exosomes coated with easily rotated $\mathrm{Ab}$ of differing specificity and also to the dual possibility to use readily selected, different therapeutic miRNA or siRNA. Together, this achieves varying Ag or oncogene specific exosome-mediated therapy, that would be much less prone to tumor escape. 
Furthermore, in a variety of cancers, treatment with anti-PD-1 or anti-PD-L1 Ab, or other analogous negative co-stimulation specific $\mathrm{Ab}$, that often is incomplete when used as $\mathrm{Ab}$ alone, could be used as an exosome coating for check point targeting to reverse tumor mediated suppression of host effector $\mathrm{T}$ cell anti-tumor reactivity. When armed with multiple check point-targeting $\mathrm{mAb}$, such therapeutic, Ag-specific exosomes might not only cover multiple target check points, making tumor escape less likely, but also could simultaneously deliver relevant inhibitory RNAs to disable the pro-oncogenetic function of involved suppressive cells [35]. Accordingly, exosomes could be constructed to inhibit cancer cell-induced immunosuppression by both, specific anti-PD1/L1 Ab coating and delivery of engineered hybridizing gene sequences encoded by selected DNA or RNA, or instead for CRISPR/cas-9 oncogene targeting [36]. Additionally, for these various scenarios of dual Ag and gene specific exosome-mediated anti-cancer therapies, the prospect of efficacious oral therapy would undoubtedly have greater patient acceptance and comfort, especially when combined with existing drug and radiotherapy that might be reduced to achieve less toxicity in the patients.

\subsection{Ab FLC Surface Binding Is Associated with 'Activated' Exosomes}

A unique feature of both, the hapten-Ag and OVA protein-Ag systems, is that the generated exosomes are able to bind selected Ag-specific Ab FLC and associate with chosen miRNA-150. These unusual binding and associating features uniquely provide both highly Ag-specific binding to targeted cells and ability to transfer gene directed, functional alterations; such as epigenetic changes. Such dual-specific targeting, in part resulting from cargo transfer, is a unique property of the exosome subpopulation we have described, as no other laboratories have yet reported these combined properties. In contrast, when exosomes are similarly prepared from normal, unmanipulated animals, they do not have either ability to be significantly coated with Ab FLC nor miRNA-150 associating properties compared to those from animals stimulated by diverse modes of positive immunization or immune tolerization.

We refer to these exosomes having the combined Ab FLC binding and miRNA associating properties as 'activated' exosomes, as they are preferentially derived from activated lymphoid cells of immunized or tolerized mice, and not unmanipulated normal donors $[4,10]$. It is currently not known what steps in immunization or tolerization induce these activation properties, nor what are the stimuli that produce these changes, that are not found on exosomes from non-immune donors. Acquisition of activation characteristics is true for exosomes of mice undergoing strong and prolonged exposure to high doses of $\mathrm{Ag}$ in tolerogenesis, or even mere two day ID immunization with proteins without an adjuvant, and to exosomes from various Ag high dose-tolerized Ab-deficient or miRNA KO mice as well.

The association of the mAb FLC with the exosome surface was determined by the ability of $\mathrm{mAb}$ FLC to bind the surface of 'activated', but not normal, exosomes. This was verified by cytometric visualization of FLC on the exosome surface (Figures 1C and 5B) [4,8]. Such surface and other activations seemed to account for acquisition of both, the ability to bind specific Ag via surface Ab FLC, that enabled mediation of Ag-specific suppressive function, and also to associate and then transfer selected miRNA for alteration of intracellular functional effects.

This Ag-specificity was demonstrated by OVA Ag-affinity column separation of the total suppressive exosome population that yielded two subpopulations (Figure 2A) [4]. These were specifically Ag-binding, Ab-coated, therefore considered 'activated', small exosomes that had the suppressive functional activity vs. Ag-non-binding and functionally inactive exosomes (Figure 2A). This suggested that, in this case, employing Ag-affinity column separation suggested that only around $10 \%$ or less of the total exosomes from immunized or tolerized animals are actually 'activated' and able to bind the $\mathrm{Ag}[4]$, or express the involved CD9 tetraspanin.

Prior studies with mast cells originally determined binding of Ab FLC to the cell membrane, that, as shown here, also apply to the surface of 'activated' exosomes. The binding of Ab FLC to the mast cell surface enabled subsequent binding of specific Ag [37]. This allowed for induction of mast cell 
degranulation and mediator release [37,38], and correlated with the activity of mast cells in several models of immunological diseases [39]. Another connected and also unusual property of the 'activated' exosomes was that there was no bioactive exosome surface binding of $\mathrm{Ab}$ free heavy chains, nor whole Ag-specific IgG of the same Ab source, despite their ability to bind the Ab FLC [4]. This was also true for the mast cell binding $[37,38]$.

\subsection{Possible Role of Membrane Lipids in EV Surface Activation}

We have formed the hypothesis that these properties of exosome activation are due to an increased content of components in their membranes. This idea is based on our unpublished findings that these vesicles have greater size (150-225 nm) than the typical exosome-like nanovesicles (50-120 nm), and by flow cytometry showing that they can have lower expression of routine molecules present on the surface of most exosomes, like MHC class I (unpublished). This suggests that there has been a filling in of an expanded surface with membrane components, that we believe are likely lipids. This would be the most immediately manipulatable surface component during exosome donor cell stimulation [40]. Furthermore, study of cellular uptake of exosomes showed that interactions with targeted cells can be modified by changing the lipid composition of their membranes [41,42].

Concerning membrane lipids and Ab FLC binding, our ideas also came from studies showing that binding of immunoglobulin FLC to human mononuclear cell subsets depends on surface lipids [43-45]. These ideas were sustained by our preliminary unpublished studies examining lipid binding of FLC. Firstly, mAb FLC were shown to have stronger binding ability to certain individual lipid components, such a phosphoethanolamine. This was determined firstly with an ELISA-type assay of lipids adsorbed on plastic wells and then bound by $\mathrm{mAb}$ FLC, quantitated by a second binding with anti-light chain $\mathrm{mAb}$ linked with enzyme and detected enzymatically. Secondly, liposomes constructed at small EV size and dominantly composed of the best individual lipid binders, like phosphoethanolamine, and less of poor Ab FLC binders like sphingomyelin, were able to bind the Ab FLC, as detected by western blotting. Thirdly, these Ab FLC-associated liposomes had biological properties that routinely composed liposomes did not have (Hutchinson and Askenase, unpublished data).

Studies are underway to similarly examine miRNA interactions with activated vs. normal exosomes. The amounts of miRNA involved in association with 'activated' OVA suppressive exosomes are likely minute, as we showed before in CS [10], and here in DTH (Figure 5E). It was hoped that biotinylation of miRNA-150 would be helpful for such analysis, since it could aid detection of the binding of miRNA to the exosome surface or associated within the 'activated' exosomes by pull-down techniques [46]. Unfortunately, this biotinylation caused inactivation of miRNA-150 biological properties (Figure 5E, Group G); as predicted in the literature [47].

\subsection{Similar 'Activated' Exosomes May Mediate RNA Transfers in Other Systems}

Lipid changes of 'activated' exosome membranes may account for their other exceptional exosoe subpopulation properties, like our unique finding that oral systemic suppressive therapy with Ag-specific exosomes can affect a strong local immune reaction at a specific cutaneous anatomical site. This may relate to the physiologically transferred functions of numerous exosomes particularly contained in mothers' milk and delivered to neonates [48-50]. The special property of these exosomes is resistance to harsh conditions in the neonatal stomach, like very low $\mathrm{pH}$ plus digestive enzymes [51,52], that also could be properties of 'activated' exosomes in the immunological systems we described [53]. RNA cargo of milk exosomes may transfer epigenetic information to neonates after intestinal absorption [54,55], perhaps via intestinal epithelial cell endocytosis [56,57], benefitting the neonatal intestine [58,59], and allowing postulated subsequent systemic transfer [60], that may influence neonatal immunity [48,49,61-64], bone formation [65,66], and development of the nervous and endocrine systems in the neonates. However, there are as yet few studies actually showing beneficial systemic effects in neonates of orally-delivered milk EV-carried miRNAs, and there is some contrary data [67]. Thus, our findings of systemic oral exosome transfer of miRNA mediated 
immune suppression strengthens the idea that milk exosomes might orally transfer systemic effects to the neonates.

Of further great relevance, there are numerous claims that among miRNAs taken orally in foods, in some cases these mixtures contain exosomes that also can pass stomach digestion for uptake systemically to affect host functional processes [68-70]. Again, there is controversy with some compelling data against this concept [67,71-74]. Note, however, that these are complex issues with many technical barriers to be overcome for definitive determinations before these issues can be settled [75-78]. Herein however, oral treatment with claimed 'activated' subsets of exosomes carrying miRNA-150 in our non-dietary system clearly showed strong and prolonged in vivo immune suppression at a particular systemic skin site. Thus, suppressive effects of orally administered, Ts cell-derived, Ag-specific exosomes (Figure 3E), delivering a particular inhibitory miRNA-150, favor the idea of transferred functionality of dietary food miRNAs, under some circumstances.

Recently, casein-specific Ts cell-derived exosomes have been shown to suppress casein-induced DTH in actively immunized mice when delivered per os in a system aimed at study of milk allergy [79]. This implies that biological functionality after oral administration is a general feature of Ts cell-derived exosomes. One can speculate that these suppressive exosomes are firstly endocytosed by intestinl epithelial or vascular endothelial cells in the small intestine and then transmitted to circulation, as observed in the case of cow's milk exosomes [56,60]. Otherwise, they may be transmitted to mucosal lymphatic tissue to induce Treg lymphocytes. However, this aspect requires much further investigation.

\subsection{Demonstration That Ag-Derived Peptides Are the Binding Targets of FLC on Ag-Specific Suppressive Exosomes}

Our prior study in the CS hapten-system showed that macrophage APC, and not the finally suppressed effector $\mathrm{T}$ cells, were the direct target of the Ag-specific suppressive exosomes [6]. We hypothesized that Ab FLC on the surface of the inhibitory exosomes bound to Ag peptides in MHC complexes on the APC surface to lead to eventual suppression by the miRNA-150-influenced APC of the effector T cells that mediate CS [30].

Our success in generation of OVA protein Ag-specific suppressive exosomes made testing of these ideas possible. Firstly, we showed binding of Ts cell-derived exosomes to OVA-coupled Sepharose on an Ag-affinity column only by the effectively suppressive minor exosome subpopulation (Figure 2A), and to an anti-CD9-coupled Ab-affinity column (Figure 1F), that strongly support our hypotheses. In addition, cytometric analysis revealed the co-expression of CD9 and Ab FLC by exosomes from both Ts and B1a cells (Figures $1 \mathrm{C}$ and $5 \mathrm{~B}$ ). To further extend these findings, we set up an ELISA with native OVA absorbed on plastic wells, and determined the binding of four different anti-OVA $\mathrm{mAb}$ rendered into FLC, as well as the isolated heavy chains, compared to whole anti-OVA IgGs. We found that binding of OVA by IgG was the strongest, heavy chains next and FLC last, but definitely detectable (Figure 6A,B). Comparing the four $\mathrm{mAb}$, there was a consistent hierarchy of binding for all chains and the whole IgG among each $\mathrm{mAb}$ type. Thus, binding native OVA by each $\mathrm{mAb}$ and its chains was different; ranging from excellent to much less in some, and to nil or nearly nil in others (Figure 6). The similar binding within a mAb IgG and its heavy and light chains likely was due to identical immunoglobulin V-region DNA sequence mutations in the producing B cells, and thus identical specificity of the translated $\mathrm{mAb}$. Conversely, the different binding between the four $\mathrm{mAb}$ likely was due to different $\mathrm{V}$-region mutations resulting in different derived $\mathrm{mAb}$ affinities for native OVA Ag determinants adsorbed on plastic.

Knowing that Ag-presenting macrophages were the target of the Ab FLC on the exosomes for mediating the final Ts cell suppression of the effector $T$ cells $[4,6]$, we further tested suppression by the four $\mathrm{mAb}$ FLC separately coating the same exosomes from Ag-tolerized, Ab-deficient $J \mathrm{H}^{\text {neg/neg }}$ mice, that gave a remarkable result. We observed a very different hierarchy in the strength of $\mathrm{mAb}$ dependent exosome-mediated suppression (Figure 7B) compared to binding of native OVA (Figure 6A,B). This 
was consistent with the idea that the Ab FLC on the suppressive exosomes bound to Ag-peptides on the APC and not to native OVA.

To investigate this further, we made a tryptic digested peptide mixture from native OVA and tested its ability to block suppression mediated by these exosomes, using different protocols. In the first experiments, the OVA peptides were incubated in vitro with the exosomes coated with two different anti-OVA mAb FLC that had mediated intermediate strength exosome suppression. In both cases we found strong reversal of suppression, when FLC-coated exosomes were blocked by OVA tryptic peptides (Figure 7E). Additionally, from past studies, we knew that the two day sera of OVA-immunized mice contain both anti-OVA IgM and also Ab FLC, derived from activated B1a cells $[9,16,80]$. Therefore, we also coated $\mathrm{JH}^{\text {neg/neg }}$ mouse Ts cell-derived exosomes with this sera, presumably containing polyclonal immune anti-OVA Ab FLC (Figure 6E), that in fact produced strong suppression (Figure 7D). Inhibitory blocking of suppression by these polyclonal Ab FLC with OVA tryptic peptides resulted in the best reversal of suppression (Figure 7E, Groups $\mathrm{G}$ and H); likely due to the polyclonal nature of the serum Ab vs. The mAb FLC. This overall result contributed significant evidence suggesting that Ab FLC coating the Ag-specific exosomes bound to OVA Ag peptides on the APC surface. This would confer the Ag-specificity of Ts cell-mediated immune tolerance [8]. We have recently reported that, in the particular circumstances, self-tolerant exosomes can be redirected toward suppression of allergen-induced DTH responses by coating with allergen-specific Ab FLC [81].

In a second protocol, the OVA peptide mixture was used to construct peptide Ag-affinity columns. Passage of the Ab FLC down this column enabled testing those that actually had bound peptide on the column in the Ag-specific exosome-mediated suppression of DTH. The same two mAb FLC, intermediately active when coating exosomes for Ag-specific suppression, and serum polyclonal anti-OVA Ab FLC, were applied to OVA peptide columns. The OVA peptide binding Ab FLC fractions were eluted from each column and then used to coat exosomes from $\mathrm{Ag}$ tolerized $\mathrm{JH}^{\text {neg/neg }}$ mice in the suppression assay. These eluted FLC, that had bound the peptide mixture, when subsequently coating these exosomes, led to strong suppression of DTH (Figure 7D). This result confirmed that those Ab FLC that can bind peptides on the column, may mediate the Ag-specificity of the suppressive exosomes (Figure 7D, Groups C, D, and E) [8].

This unanticipated result can be seen as further evidence that the binding of the anti-OVA Ab FLC on the suppressive exosomes is likely to OVA peptides complexed in MHC on the APC surface. Thus, an explanation may be due to the manner of binding peptides by Ab FLC in the ELISA compared to FLC on the exosome surface that bind peptides in MHC. In the ELISA, there is only binding of low-affinity, isolated Ab FLC dispersed in solution to the peptides adsorbed on the artificial plastic surfaces in non-physiological conformations. In comparison, the in vivo measured, Ag-specific exosome-mediated suppression depends on FLC that are not free but linked to the exosome surface. Here, the mAb FLC are not dispersed but in multiples closely together on the exosome surface, turning a series of low affinity bindings into far greater avidity for binding Ag determinant of physiological conformation when complexed with MHC, which was confirmed in vitro in ELISA-based assay (Figure 7F). However, more direct study of $\mathrm{mAb}$ FLC binding to the peptide-MHC complex will be needed to prove this point in vivo.

\subsection{Characteristics of Ts Cell-Derived Exosomes}

The current study revealed that OVA-induced DTH effector cells are suppressed by Ts cell-derived EVs of a small size (around $150 \mathrm{~nm}$ ). These bilamellar vesicles are strongly positive for CD9 and CD81 tetraspanins but weakly express CD63 marker (Figure 1). Additionally, our previous reports demonstrated that the buoyant fraction of Ts cell-derived EVs is responsible for the observed suppressive activity $[4,81]$. They are concentrated by ultracentrifugation from the cell culture supernatant earlier deprived of cellular debris and filtered down to $0.22 \mu \mathrm{m}$ [82]. Thus, the light small EV subpopulation were called exosomes. However, it should be stressed that each cell produces very heterogeneous populations of EVs differing in size and origin [13]. Specific subtypes of small EVs can be classified 
according to displayed pattern of markers, including variability in tetraspanin expression [82]. Besides, the complexity of EVs makes that yielded subpopulations of EVs vary across the methods used for their purification prior to functional studies. Thus, more detailed characteristics of Ts cell-derived exosomes remains a subject of our further investigation.

\subsection{Summary of the New Findings of Biological and Clinical Significance of the Ag-and miRNA-Specific Exosomes That Suppress OVA Protein-Induced DTH}

New findings brought by our current studies could be summarized into several main points. (i) Uniquely, suppressive function depends on exosomes consisting of components from two lymphocyte types ( $\mathrm{T}$ and B cells). (ii) Ag-specificity in DTH suppression is due to exosome surface coating with anti-OVA Ab FLC. (iii) This Ag-specificity was definitively demonstrated by reciprocal functional suppression testing of two distinct protein-specific suppressive exosomes. (iv) Also, there was definitive demonstration that T or B cell exosome-mediated suppression in DTH is mediated by delivered inhibitory miRNA-150. (v) Systemic suppression of DTH could be achieved in vivo by administration of single physiological doses of exosomes; remarkably including oral administration. (vi) Strong, systemic suppression of maximal in vivo DTH responses at a given peripheral tissue site was observed over several days after administration of a single physiological dose of Ab FLC coated and miRNa-150 delivering exosomes. (vii) Exosomes suppressing DTH could be constructed with chosen dual Ag-specific targeting and the transfer of selected miRNA-encoded epigenetic functional effects by mixing and matching chosen surface Ab FLC and selected miRNA. (viii) These exosomes mediated suppression by very low miRNA-150 associating doses. (ix) Determination that the Ab FLC coating the suppressive exosomes likely binds OVA peptides that are complexed in MHC on the APC surface was shown firstly by comparing in vitro binding of the Ab FLC to OVA, compared to strength of suppression when coating exosomes from Ag-tolerized, Ab-deficient $\mathrm{JH}^{\text {neg/neg }}$ mice; and secondly by different peptide inhibition protocols.

To summarize, Ag-specific, Ab FLC-dependent, 'activated' exosome delivery of suppressive miRNA-150 via targeted binding of Ag-peptides in MHC on APC provides a new mechanism of immune regulation with great clinical significance, since it employs natural physiological exosomes that can be given orally and fashioned for both chosen Ag-specific targeting and selected miRNA-specific functional alterations of targeted cells that can last for several days.

\section{Materials and Methods}

\subsection{Mice}

Nine to 10-week-old CBA/J, BALB/c, JH knock out (JH'neg/neg), C57BL/6 or miRNA-150 knock out (miRNA-150 neg/neg) male mice from Jackson Laboratories (Bar Harbor, ME, USA) or CBA mice from the Breeding Unit of the Jagiellonian University Medical College, Faculty of Medicine (Krakow, Poland) were fed autoclaved food and water ad libitum. All experiments were performed according to the guidelines of Ethics Committees of Yale (approval no. 07381) and Jagiellonian (approval no. 122/2013 and 88/2017) Universities.

\subsection{Antigens, Reagents, and Culture Media}

The following reagents were used: ovalbumin (OVA), serum-free Mishell-Dutton medium, RPMI-1640, minimal essential medium with amino acids, HEPES, 2-mercaptoethanol (Sigma-Aldrich, St Louis, MO, USA), keyhole limpet hemocyanin (KLH, Stellar Biotechnologies, Port Hueneme, CA, USA), Dulbecco's phosphate-buffered saline (DPBS), penicillin/streptomycin, sodium pyruvate, L-glutamine (Gibco Life Technologies, Grand Island, NY), acetone, ethanol, glucose (P.O.Ch., Gliwice, Poland), EDC (1-ethyl-3-(3-dimethylaminopropyl)-carbodiamide, Pierce, Thermo Fisher Scientific, Waltham, MA, USA), EDTA (BDH, Poole, UK), extra virgin olive oil (Basso Fedelee Figli, San Michele di Serino, Italy). 


\subsection{Generation of Ts cell-Derived, Protein Ag-Specific, Suppressive Exosomes}

Ts cells from OVA Ag-tolerized mice releasing suppressive exosomes were induced in an analogous manner to the tolerogenic procedures described in CS [4]. Thus, mice were injected IV on days 0 and 4 with $0.2 \mathrm{~mL}$ of a freshly prepared 10\% DPBS suspension of syngeneic erythrocytes conjugated with OVA or, in some instances, with KLH protein Ag. We determined in preliminary experiments that EDC is an efficient activating agent for the coupling of protein Ag to erythrocyte membrane proteins. For full tolerogenesis, these IV treatments were followed by intradermal (ID) immunization on two consecutive days 8 and 9 with a total of $0.2 \mathrm{~mL}$ of a $0.5 \mathrm{mg} / \mathrm{mL}$ OVA each time (100 $\mu \mathrm{g}$, injected into four sites in the abdominal areas at $25 \mu \mathrm{g}$ per site), or similarly $\mathrm{KLH}$, both used as a $0.9 \% \mathrm{NaCl}$-solution and without adjuvant. After lymph node and spleen collection on day 11, single cell suspensions were cultured at $37^{\circ} \mathrm{C}$ in protein-free Mishell-Dutton medium at a concentration of $2 \times 10^{7}$ cells $/ \mathrm{mL}$ for $48 \mathrm{~h}$. To enrich exosomes, the resulting culture supernatant was subsequently centrifuged at $300 \times g$ and then $3000 \times \mathrm{g}$ for $10 \mathrm{~min}$, then filtered through 0.45- and then 0.22-micrometer molecular filters (Miltenyi Biotec, Waltham, MA, USA) and finally ultracentrifuged twice at $100,000 \times \mathrm{g}$ for $70 \mathrm{~min}$ at $4{ }^{\circ} \mathrm{C}$ [4]. The resulting pellet was resuspended in DPBS and used as OVA Ag-specific (or KLH Ag-specific) exosomes [4]. This pellet containing OVA-specific Ts cell-derived exosomes was absorbed onto copper grids and negatively stained with $3 \%$ uranyl acetate, and then visualized under transmission electron microscope (JEOL JEM2100, Tokyo, Japan). Furthermore, it was subjected to nanoparticle tracking analysis (NTA, Nanosight, Malvern, UK) [4].

In some instances prior to culture, mouse lymph node and spleen cells from Ag-tolerized donors, were depleted of either $\mathrm{CD}^{+}$or $\mathrm{CD}^{+}$cells by incubation with, respectively, anti-CD3 or anti-CD8 monoclonal IgG antibodies, and rabbit complement for $60 \mathrm{~min}$ in $37^{\circ} \mathrm{C}$ water-bath. Afterwards, dead cells were removed by discontinuous gradient centrifugation on Ficoll $(1.077 \mathrm{~g} / \mathrm{mL}$, GE Healthcare, Chicago, IL, USA).

In some experiments, actively tolerized mice were ear challenged on day 11 , and subsequent ear swelling responses were measured as described below. In some instances, tolerized and actively immunized mice were depleted of clodronate-sensitive cells (i.e., macrophages) by IP injection of $0.2 \mathrm{~mL}$ of clodronate liposomes (Department of Molecular Cell Biology, Vrije University, Amsterdam, the Netherlands) in PBS, at $24 \mathrm{~h}$ before ear challenge [6].

\subsection{In Vivo Treatment of Mice Actively Immunized with OVA with Suppressive Exosomes Injected at the Peak of DTH Response}

Mice were immunized ID with a total of $100 \mu \mathrm{g}$ of OVA, as described above, and 5 days later DTH ear swelling was elicited by ID injection of $10 \mu \mathrm{L}$ of OVA $0.9 \% \mathrm{NaCl}$ solution $(0.5 \mathrm{mg} / \mathrm{mL}$, thus $5 \mu \mathrm{g}$ per ear) into both ears. The pellet containing OVA Ag- or KLH Ag-specific suppressive exosomes was used for treatment of the mice actively ID immunized for elicitation of OVA-specific DTH either at immunization, or just before ear challenge or at the peak of the response $24 \mathrm{~h}$ after ear challenge with OVA Ag, at a dose of $1 \times 10^{10} \mathrm{EVs}$ per mouse [11]. These mice were systemically IP injected with the DPBS suspension of exosomes at a dose of about $1 \times 10^{10}$ nanovesicles per recipient. This model allowed testing of Ag-specificity of exosome action. Subsequent ear thickness was measured with an engineer's micrometer daily up to $120 \mathrm{~h}$ after challenge by a blinded observer [4,12].

To calculate the increase in ear thickness indicating strength of DTH, values of background ear thickness, measured before ear challenge, were subtracted from values of ear thickness at particular time points after ear challenge. Furthermore, to evaluate the net swelling response, mean ear thickness increase in non-immunized but similarly OVA Ag challenged littermate control mice was subtracted from the ear thickness increase measured in each ear of mouse of each control or experimental group. In general, groups consisted of 5 mice and experiments were repeated 2-4 times. The average ear swelling was expressed as the delta \pm standard error (SE), after subtraction of the negative control value. The two-tailed Student $t$-test or one-way analysis of variance (ANOVA) with post hoc RIR 
Tukey test were used to assess the significance of differences between groups, with $p$ values of less than 0.05 taken as the minimum level of statistical significance.

Exosome counts were estimated by nanoparticle tracking analysis (Nanosite, Malvern, UK). The dose used for treatment of actively immunized mice was considered physiological, since this is the average number of exosomes per $\mathrm{ml}$ of blood in normal unmanipulated mice.

Where indicated, exosomes either derived from cultures of Ts-cells or derived from early two day OVA immune B1 a cell-derived supernatants and then associated in vitro with inhibitory miRNA-150, were systemically administered, at the same doses, but in different volumes of DPBS (0.2-0.5 mL), directly to actively immunized mice via IV, IP, or ID routes. Furthermore and most importantly, the same suppressive exosomes at the same dose were also administered orally (per os, $\mathrm{PO}$ ) using a gastric feeding tube. For all of the compared systemic exosome treatments, suppressive and control exosomes were administered just after measurement of the 24-h peak of active ear swelling response. In the case of PO delivery of the exosomes, mice were kept fasting for $2 \mathrm{~h}$ before and $1 \mathrm{~h}$ after administration of the suppressive exosomes.

\subsection{In Vitro Treatment of OVA DTH Effector Cell Mixture with Exosomes, Prior to Their Adoptive Transfer to Naive Recipients}

OVA DTH-effector cells were obtained from mixed spleen and lymph node cells of mice actively sensitized by ID multiple injections of a total of $100 \mu \mathrm{g}$ OVA in plain $0.9 \% \mathrm{NaCl}$ (as described above) and harvested at day 4 after immunization [4,11]. OVA Ag-specific Ts-cell-derived, suppressive exosomes were used at the same dose of $1 \times 10^{10} \mathrm{EVs}$ for in vitro pulsing of a mixture of DTH-effector T cells and APC, at $7 \times 10^{7}$ total lymphoid cells to be transferred per eventual recipient. Then, the exosome pulsed DTH effector cells were adoptively transferred into naive recipients, in which $24 \mathrm{~h}$ later DTH ear swelling responses were elicited by ID injection of $10 \mu \mathrm{L}$ of OVA $0.9 \% \mathrm{NaCl}$ solution $(0.5 \mathrm{mg} / \mathrm{mL}$, thus $5 \mu \mathrm{g}$ per ear). Ears were measured for thickness with an engineer's micrometer (Mitutoyo, Kawasaki, Japan), at $24 \mathrm{~h}$ after challenge. Results were statistically analyzed as described above.

4.6. Polyribonucleotide Treatments to Induce Suppressive Activity of Non-Suppressive Exosomes, or to Block Their Suppressive Activity, Prior to Incubation with DTH Effector Cell Mixture

In some instances, Ts-cell-derived, OVA-specific exosomes were pretreated with a polynucleotide antagonist of miRNA-150 (anti-miRNA-150, Dharmacon, Lafayette, CO, USA), at a dose of $3 \mu \mathrm{g}$ per total exosomes $\left(10^{10}\right)$ per each of eventual five recipients of exosome-pulsed DTH-effector cells $\left(7 \times 10^{7}\right.$, the average number of cells transferred IV to each recipient). After washing away of unbound anti-miR-150 molecules by ultracentrifugation, the mixture of DTH effector cells and miRNA antagonist associated exosomes were incubated in a $37^{\circ} \mathrm{C}$ water bath for $30 \mathrm{~min}$. Then, the exosome treated and control DTH effector cells were adoptively transferred into naive recipients, as described above.

In other experiments, exosomes from Ag-tolerized miRNA-150 neg/neg mice were treated in a $37^{\circ} \mathrm{C}$ water-bath for $30 \mathrm{~min}$ with synthetic miRNA-150 in a dose of $3 \mu \mathrm{g}$ per $10^{10}$ exosomes to be used subsequently to treat the DTH-effector cell mixture $\left(7 \times 10^{7}\right)$, per single eventual recipient. Then, through ultracentrifugation, we removed excessive, exosome-non-associated miRNA-150 molecules and used the resulting miRNA-150 pulsed exosomes to treat the DTH effector cells in vitro prior to washing away the exosomes and then IV adoptive transfer of the cells.

\subsection{Ab FLC Coating, OVA Peptide Blocking, and OVA Ag or Anti-CD9 Affinity Column Chromatography of Ts-Cell-Derived Exosomes}

Ts cell-derived exosomes from Ag tolerized $\mathrm{JH}^{\text {neg/neg }}$ mice were non-suppressive due to the lack of surface FLC, but nonetheless carried miRNA-150. These were converted for Ag-specific suppression by surface coating with various anti-OVA FLC (derived from either four different monoclonal Ab or immune serum of 2 day OVA-immunized mice) by incubation overnight on ice. This was followed by 
ultracentrifugation at $100,000 \times g$ to remove unbound FLC into the supernatant from the Ab FLC-coated exosomes in the pellet.

In other instances, OVA-specific Ts cell-derived exosomes endogenously coated with B1 a cell-derived Ab FLC, were initially blocked with tryptic digested OVA peptides by a preliminary 2-h incubation in $37^{\circ} \mathrm{C}$ water-bath. This was followed by ultracentrifugation to remove excessive OVA peptides into the supernatant from peptide-blocked exosomes in the pellet. In yet other cases, these OVA-specific, Ts-cell-derived exosomes were separated by affinity chromatography on columns filled with Sepharose coupled with either native OVA Ag or with purified anti-CD9 monoclonal antibodies [4].

\subsection{Generation of B1 a Cell-Derived Exosomes and Their In Vitro Association with miRNA-150}

To induce very early activated Ag-specific B1 a cells, mice were immunized with OVA protein Ag by ID injections of total volume of $0.2 \mathrm{~mL}$ for four separate simultaneous intradermal injections of a $0.5 \mathrm{mg} / \mathrm{mL}$ OVA solution in $0.9 \% \mathrm{NaCl}$ (total ID immunizing dose of $100 \mu \mathrm{g}$ OVA) without adjuvants on days 0 and 1 [11]. Then, on day 3, lymph nodes and spleens containing the immune B1 a cells were collected and single cell suspensions were cultured in protein-free Mishell-Dutton medium at a concentration of $2 \times 10^{7}$ cells $/ \mathrm{mL}$ for $48 \mathrm{~h}$ [9]. The resulting culture supernatant was subsequently centrifuged at $300 \times g$ and then $3000 \times g$ for $10 \mathrm{~min}$, filtered through 0.45 - and then 0.22 -micrometer molecular filters and then ultracentrifuged twice at $100,000 \times g$ for $70 \mathrm{~min}$ at $4{ }^{\circ} \mathrm{C}$. The pellet presumably containing B1 a cell-derived exosomes was absorbed onto copper grids and negatively stained with osmium tetroxide, and then visualized under transmission electron microscope (FEI Tecnai T12, LaB6, Thermo Fisher Scientific, Waltham, MA, USA).

The resulting pellet containing enriched Ag-specific B1 a cell-derived exosomes was resuspended in DPBS. Then, where indicated, the Ag-specific B1 a cell-derived, non-suppressive exosomes that received no endogenous miRNA-150, since they were from immunized and not tolerized mice, were associated in vitro with synthetic miRNA-150. This was achieved by incubation in $37^{\circ} \mathrm{C}$ water-bath for $30 \mathrm{~min}$ with miRNA-150 at a dose of $3 \mu \mathrm{g}$ per $10^{10}$ nanovesicles. These exogenously miRNA-150-associated exosomes were subsequently used to pulse $7 \times 10^{7} \mathrm{DTH}$-effector cells per single recipient. Prior to incubation with the DTH-effector cells, the Ag-specific, B1 a cell-derived exosomes that had been incubated with free miRNA-150 for association, were washed by a single ultracentrifugation to remove excessive, exosome-non-associated miRNA-150 molecules.

\subsection{Cytometric Analysis of Exosomes and Evaluating the Presence of Antibody Light Chains in Two-Day Serum of OVA-Immunized Mice}

Aldehyde/sulphate latex beads (4 $\mu \mathrm{m}$, Life Technologies, Thermo-Fisher Scientific, Carlsbad, CA, USA) were incubated in DPBS with OVA-specific exosomes derived from Ts cells or B1 a cells at room temperature for $2 \mathrm{~h}$ with gentle agitation. Afterwards, exosome-coated beads were blocked with $100 \mathrm{mM}$ glycine, washed, resuspended in DPBS, and stained with fluorescein isothiocyanate (FITC)-conjugated mAb against mouse kappa light chains (BD Biosciences, San Diego, CA, USA) and/or phycoerythrin (PE)-conjugated mAb against mouse CD9, CD63 or CD81 tetraspanins (BD Biosciences, San Diego, CA, USA). Alternatively, the aldehyde/sulphate latex beads were coated with native OVA $\mathrm{Ag}$ by overnight incubation at $4{ }^{\circ} \mathrm{C}$ with gentle agitation, and then, after washing, were incubated with 2 day immune serum from the ID OVA-immunized mice. After washing, these OVA-coupled beads were stained against mouse antibody kappa light chains to evaluate the eventual presence of anti-OVA FLC in the serum.

\subsection{ELISA for Assessment of Binding to Native OVA, OVA Tryptic Peptides, or OVA 323-339 Peptide by} Various Anti-OVA mAb FLC

Isolated OVA-specific $\mathrm{mAb} F L C$ and isolated $\mathrm{mAb}$ free heavy chains were made from four different OVA-specific mAb IgGs (clones F2 3.58, 7 E9.17, 7 H7.E1, and 11 B.1) from the Frank Fitch collection, 
University of Chicago, that were kindly provided by Anne Sperling. The whole IgGs were reduced and alkylated to separate heavy and light chains in the laboratory of Frank Redegeld at the University of Utrecht, the Netherlands. Proteins were eluted from columns with $6 \mathrm{M}$ guanidine and subsequently loaded onto a gel filtration column (HiLoad 16/60 Superdex 200 pg, GE Healthcare, Chicago, IL, USA) to separate anti-OVA mAb heavy and light chains (FLC). Subsequently, samples were dialyzed versus PBS to remove guanidine and then concentrated.

Then, OVA Ag-specific mAb FLC, heavy chains, and whole IgGs were added to quadruplicate microwells of high binding ELISA plates that previously were coated with native OVA $(25 \mu \mathrm{g} / \mathrm{mL})$. After Ag coating, the plates were blocked with PBS/10\% FBS/0.05\% Tween-20 for $1 \mathrm{~h}$ at room temperature, washed and finally incubated with the four separate OVA-Ag-specific Ab FLC, heavy chains, or whole IgG1, all diluted in PBS/1\%FBS/0.05\% Tween-20 (assay buffer) at multiple serial dilutions for $1 \mathrm{~h}$ at room temperature. For detection of bound $\mathrm{mAb}$ FLC, heavy chains and whole IgGs, plates were subsequently incubated with $0.1 \mu \mathrm{g} / \mathrm{mL}$ HRP-labeled goat anti-mouse $\mathrm{k}$ light chain $\mathrm{Ab}$ (Southern Biotech, Birmingham, AL 35260, UK), diluted in assay buffer for $1 \mathrm{~h}$ at room temperature. For detection of $\mathrm{mAb}$ heavy chains, $0.1 \mu \mathrm{g} / \mathrm{mL}$ HRP-labeled goat anti-mouse IgG/IgM H+L Ab (Jackson Labs, Bar Harbor, ME, USA) was used. Finally, TMB was used as a substrate for the enzymatic reaction, terminated by adding $1 \mathrm{M} \mathrm{H}_{2} \mathrm{SO}_{4}$ after $23 \mathrm{~min}$ in the case of Ab FLC assaying or after $3 \mathrm{~min}$ in all other cases. Between incubation steps, wells were washed three times with PBS/0.05\% Tween-20. To evaluate the binding of FLC to OVA 323-339 peptide, plate wells were coated with OVA 323-339 peptide at a concentration of $10 \mu \mathrm{g} / \mathrm{mL}$, and assay was developed as above. To compare binding of FLC to native OVA and OVA tryptic peptides, plate wells were coated with OVA preparations at a concentration of $100 \mu \mathrm{g} / \mathrm{mL}$, and the assay was performed as above, but the reaction was stopped by adding $1 \mathrm{M} \mathrm{H}_{3}$ $\mathrm{PO}_{4}$ after 8 min.

\subsection{ELISA for Assessment of Binding to Native OVA, OVA Tryptic Peptides, or OVA 323-339 Peptide by Either JHnegheg Mouse Exosomes Coated with Anti-OVA mAb FLC or Wild Type Mouse Exosomes}

Plate wells were coated with either native OVA, OVA tryptic peptides or OVA 323-339 peptide, all at a concentration of $100 \mu \mathrm{g} / \mathrm{mL}$ overnight at $4{ }^{\circ} \mathrm{C}$ and then blocked with $2 \%$ BSA for $2 \mathrm{~h}$ at room temperature. Then exosome samples (approximately $5 \times 10^{9}$ exosomes per well) were added to particular wells and incubated overnight at $4{ }^{\circ} \mathrm{C}$. After washing with $0.1 \%$ BSA in PBS, $100 \mu \mathrm{L} /$ well of rat monoclonal IgG antibody anti-mouse CD9 (BD Biosciences, Franklin Lakes, NJ, USA) was added at a concentration of $4 \mu \mathrm{g} / \mathrm{mL}$ and plate was incubated for $2 \mathrm{~h}$ at room temperature. After washing, $100 \mu \mathrm{L} /$ well of HRP-conjugated rabbit anti-rat IgG antibody (Invitrogen, ThermoFisher, Waltham, MA, USA) was added at a concentration of $2 \mu \mathrm{g} / \mathrm{mL}$ and plate was incubated for $1 \mathrm{~h}$ at room temperature. After extensive washing, $100 \mu \mathrm{L} /$ well of TMB substrate was added and the reaction was terminated after $8 \mathrm{~min}$ by adding $50 \mu \mathrm{L} /$ well of $1 \mathrm{M} \mathrm{H}_{3} \mathrm{PO}_{4}$.

Supplementary Materials: Supplementary materials can be found at http:/www.mdpi.com/1422-0067/21/15/ 5540/s1. Figure S1. The general scheme of Ag immunization and challenge testing of mice administered ID with ovalbumin (OVA) without an adjuvant to induce DTH responses. Figure S2. DTH induced by ID immunization with OVA is prevented by prior IV injection of high doses of OVA-linked autologous RBC that induce tolerance to OVA, due to suppressor T cells producing exosomes able to inhibit adoptive cell transfer of OVA-immune DTH.

Author Contributions: Conceptualization, K.N., K.B., W.P., and P.W.A.; Methodology, K.N. and K.B.; Validation, K.N., K.B., and P.W.A.; Formal analysis, K.N. and K.B.; Investigation, K.N., K.B., and T.G.K.; Data curation, K.N. and K.B.; Writing-original draft preparation, P.W.A.; Writing-review and editing, K.N. and K.B.; Visualization, K.N., K.B., and P.W.A.; Supervision, K.B. and P.W.A.; Project administration, K.B. and P.W.A.; Funding acquisition, K.B. and P.W.A. All authors have read and agreed to the published version of the manuscript.

Funding: This research was funded by Polish National Science Centre (NCN), grant number 2013/11/B/NZ6/02041 (K.B.) and by National Institutes of Health (NIH), grants number AI-076366, AI-07174, and AI-1053786 (P.W.A.). The purchase of ultracentrifuge for Department of Immunology, Jagiellonian University Medical College, Krakow, was supported by the Polish Ministry of Science and Higher Education, grant number 6354/IA/156/2013. 
Acknowledgments: We are indebted to Peter Cresswell (Yale) for his advice and guidance in the APC and peptide aspects of this work, to Joan Steitz (Yale) of her advice on the miRNA aspects, and to Bernadeta Nowak (Jagiellonian University Medical College) for her valuable advice on flow cytometry analysis of exosomes. We are very grateful to Rafal Szatanek (Jagiellonian University Medical College) for supporting Nanoparticle Tracking Analysis of the vesicles as well as to Olga Woznicka (Jagiellonian University), and to Lab Members of Electron Microscopy Unit (Yale School of Medicine) for their precious help with transmission electron microscopy of the vesicles. Results showed in the Figure 1A,B, Figure 2A, Figure 3A,B,D,E, Figure 4B, Figure 5D-F, Figure 6E, and Figure 7F were obtained from experiments supported by Polish National Science Centre (NCN, 2013/11/B/NZ6/02041).

Conflicts of Interest: The authors declare no conflict of interest. The funders had no role in the design of the study; in the collection, analyses, or interpretation of data; in the writing of the manuscript, or in the decision to publish the results.

\section{Abbreviations}

$\begin{array}{ll}\mathrm{Ab} & \text { Antibody } \\ \mathrm{Ag} & \text { Antigen } \\ \mathrm{APC} & \text { Antigen-presenting cell } \\ \mathrm{CAR} & \text { Chimeric antigen receptor } \\ \mathrm{CS} & \text { Contact sensitivity } \\ \mathrm{DTH} & \text { Delayed-type hypersensitivity } \\ \text { ELISA } & \text { Enzyme-linked immunosorbent assay } \\ \text { exRNA } & \text { Extracellular ribonucleic acid } \\ \text { EVs } & \text { Extracellular vesicles } \\ \text { FLC } & \text { Free light chains } \\ \text { ID } & \text { Intradermal } \\ \text { IP } & \text { Intraperitoneal } \\ \text { IV } & \text { Intravenous } \\ \text { KLH } & \text { Keyhole limpet hemocyanin } \\ \text { OVA } & \text { Ovalbumin } \\ \text { OVA-RBC } & \text { Ovalbumin-coupled red blood cells } \\ \text { OX } & \text { Oxazolone } \\ \text { PO } & \text { Per os, oral administration } \\ \text { RBC } & \text { Red blood cells } \\ \text { TNP } & \text { Trinitrophenol } \\ \text { Treg cell } & \text { Regulatory T cell } \\ \text { Ts cell } & \text { Suppressor T cell } \\ \text { WT } & \text { Wild type } \\ & \end{array}$

\section{References}

1. Asherson, G.L.; Ptak, W. Contact and delayed hypersensitivity in the mouse. III. Depression of contact sensitivity by pre-treatment with antigen and the restoration of immune competence in tolerant mice by normal lymphoid and bone marrow cells. Immunology 1970, 18, 99-106. [PubMed]

2. Asherson, G.L.; Zembala, M. T cell suppression of contact sensitivity in the mouse. III. The role of macrophages and the specific triggering of nonspecific suppression. Eur. J. Immunol. 1974, 4, 804-807. [CrossRef]

3. Askenase, P.W.; Asherson, G.L. Contact sensitivity to oxazolone in the mouse. VIII. Demonstration of several classes of antibody in the sera of contact sensitized and unimmunized mice by a simplified antiglobulin assay. Immunology 1972, 23, 289-298. [PubMed]

4. Bryniarski, K.; Ptak, W.; Jayakumar, A.; Püllmann, K.; Caplan, M.J.; Chairoungdua, A.; Lu, J.; Adams, B.D.; Sikora, E.; Nazimek, K.; et al. Antigen-specific, antibody-coated, exosome-like nanovesicles deliver suppressor T-cell microRNA-150 to effector T cells to inhibit contact sensitivity. J. Allergy Clin. Immunol. 2013, 132, 170-181. [CrossRef] [PubMed]

5. Ptak, W.; Asherson, G.L. Contact and delayed hypersensitivity in the mouse. II. The role of different cell populations. Immunology 1969, 17, 769-775. [PubMed] 
6. Nazimek, K.; Ptak, W.; Nowak, B.; Ptak, M.; Askenase, P.W.; Bryniarski, K. Macrophages play an essential role in antigen-specific immune suppression mediated by T CD8 ${ }^{+}$cell-derived exosomes. Immunology 2015, 146, 23-32. [CrossRef] [PubMed]

7. Askenase, P.W.; Szczepanik, M.; Itakura, A.; Kiener, C.; Campos, R.A. Extravascular T-cell recruitment requires initiation begun by Valpha14+ NKT cells and B-1 B cells. Trends Immunol. 2004, 25, 441-449. [CrossRef] [PubMed]

8. Nazimek, K.; Askenase, P.W.; Bryniarski, K. Antibody light chains dictate the specificity of contact hypersensitivity effector cell suppression mediated by exosomes. Int. J. Mol. Sci. 2018, 19, 2656. [CrossRef]

9. Askenase, P.W.; Bryniarski, K.; Paliwal, V.; Redegeld, F.; Groot Kormelink, T.; Kerfoot, S.; Hutchinson, A.T.; van Loveren, H.; Campos, R.; Itakura, A.; et al. A subset of AID-dependent B-1 a cells initiates hypersensitivity and pneumococcal pneumonia resistance. Ann. N. Y. Acad. Sci. 2015, 1362, 200-214. [CrossRef]

10. Bryniarski, K.; Ptak, W.; Martin, E.; Nazimek, K.; Szczepanik, M.; Sanak, M.; Askenase, P.W. Free extracellular miRNA functionally targets cells by transfecting exosomes from their companion cells. PLoS ONE 2015, 10, e0122991. [CrossRef]

11. Szczepanik, M.; Akahira-Azuma, M.; Bryniarski, K.; Tsuji, R.F.; Kawikova, I.; Ptak, W.; Kiener, C.; Campos, R.A.; Askenase, P.W. B-1 B cells mediate required early T cell recruitment to elicit protein-induced delayed-type hypersensitivity. J. Immunol. 2003, 171, 6225-6235. [CrossRef]

12. Zemelka-Wiacek, M.; Majewska-Szczepanik, M.; Pyrczak, W.; Szczepanik, M. Complementary methods for contact hypersensitivity (CHS) evaluation in mice. J. Immunol. Methods 2013, 387, 270-275. [CrossRef] [PubMed]

13. Jeppesen, D.K.; Fenix, A.M.; Franklin, J.L.; Higginbotham, J.N.; Zhang, Q.; Zimmerman, L.J.; Liebler, D.C.; Ping, J.; Liu, Q.; Evans, R.; et al. Reassessment of exosome composition. Cell 2019, 177, 428-445.e18. [CrossRef] [PubMed]

14. Kerfoot, S.M.; Szczepanik, M.; Tung, J.W.; Askenase, P.W. Identification of initiator B cells, a novel subset of activation-induced deaminase-dependent B-1-like cells that mediate initiation of contact sensitivity. J. Immunol. 2008, 181, 1717-1727. [CrossRef] [PubMed]

15. Paliwal, V.; Tsuji, R.F.; Szczepanik, M.; Kawikova, I.; Campos, R.A.; Kneilling, M.; Röcken, M.; Schuurman, J.; Redegeld, F.A.; Nijkamp, F.P.; et al. Subunits of IgM reconstitute defective contact sensitivity in B-1 cell-deficient xid mice: Kappa light chains recruit T cells independent of complement. J. Immunol. 2002, 169, 4113-4123. [CrossRef] [PubMed]

16. Yamamoto, N.; Kerfoot, S.M.; Hutchinson, A.T.; Dela Cruz, C.S.; Nakazawa, N.; Szczepanik, M.; Majewska-Szczepanik, M.; Nazimek, K.; Ohana, N.; Bryniarski, K.; et al. Expression of activation-induced cytidine deaminase enhances the clearance of pneumococcal pneumonia: Evidence of a subpopulation of protective anti-pneumococcal B1 a cells. Immunology 2016, 147, 97-113. [CrossRef]

17. Bianco, N.R.; Kim, S.H.; Ruffner, M.A.; Robbins, P.D. Therapeutic effect of exosomes from indoleamine 2,3-dioxygenase-positive dendritic cells in collagen-induced arthritis delayed-type hypersensitivity disease models. Arthritis Rheum. 2009, 60, 380-389. [CrossRef]

18. Choudhuri, K.; Llodrá, J.; Roth, E.W.; Tsai, J.; Gordo, S.; Wucherpfennig, K.W.; Kam, L.C.; Stokes, D.L.; Dustin, M.L. Polarized release of T-cell-receptor-enriched microvesicles at the immunological synapse. Nature 2014, 507, 118-123. [CrossRef]

19. Hao, S.; Yuan, J.; Xiang, J. Nonspecific CD4(+) T cells with uptake of antigen-specific dendritic cell-released exosomes stimulate antigen-specific CD8(+) CTL responses and long-term T cell memory. J. Leukoc. Biol. 2007, 82, 829-838. [CrossRef]

20. Kim, S.H.; Lechman, E.R.; Bianco, N.; Menon, R.; Keravala, A.; Nash, J.; Mi, Z.; Watkins, S.C.; Gambotto, A.; Robbins, P.D. Exosomes derived from IL-10-treated dendritic cells can suppress inflammation and collagen-induced arthritis. J. Immunol. 2005, 174, 6440-6448. [CrossRef]

21. Kim, S.H.; Bianco, N.; Menon, R.; Lechman, E.R.; Shufesky, W.J.; Morelli, A.E.; Robbins, P.D. Exosomes derived from genetically modified DC expressing FasL are anti-inflammatory and immunosuppressive. Mol. Ther. 2006, 13, 289-300. [CrossRef] [PubMed]

22. Kim, S.H.; Bianco, N.R.; Shufesky, W.J.; Morelli, A.E.; Robbins, P.D. Effective treatment of inflammatory disease models with exosomes derived from dendritic cells genetically modified to express IL-4. J. Immunol. 2007, 179, 2242-2249. [CrossRef] [PubMed] 
23. Kim, S.H.; Bianco, N.R.; Shufesky, W.J.; Morelli, A.E.; Robbins, P.D. MHC class II+ exosomes in plasma suppress inflammation in an antigen-specific and Fas ligand/Fas-dependent manner. J. Immunol. 2007, 179, 2235-2241. [CrossRef] [PubMed]

24. Mu, C.; Zhang, X.; Wang, L.; Xu, A.; Ahmed, K.A.; Pang, X.; Chibbar, R.; Freywald, A.; Huang, J.; Zhu, Y.; et al. Enhanced suppression of polyclonal CD8+25+ regulatory $\mathrm{T}$ cells via exosomal arming of antigen-specific peptide/MHC complexes. J. Leukoc. Biol. 2017, 101, 1221-1231. [CrossRef] [PubMed]

25. Okoye, I.S.; Coomes, S.M.; Pelly, V.S.; Czieso, S.; Papayannopoulos, V.; Tolmachova, T.; Seabra, M.C.; Wilson, M.S. MicroRNA-containing T-regulatory-cell-derived exosomes suppress pathogenic T helper 1 cells. Immunity 2014, 41, 89-103. [CrossRef] [PubMed]

26. Ruffner, M.A.; Kim, S.H.; Bianco, N.R.; Francisco, L.M.; Sharpe, A.H.; Robbins, P.D. B7-1/2, but not PD-L1/2 molecules, are required on IL-10-treated tolerogenic DC-derived exosomes for in vivo function. Eur. J. Immunol. 2009, 39, 3084-3090. [CrossRef]

27. Song, J.; Huang, J.; Chen, X.; Teng, X.; Song, Z.; Xing, Y.; Wang, M.; Chen, K.; Wang, Z.; Yang, P.; et al. Donor-derived exosomes induce specific regulatory $\mathrm{T}$ cells to suppress immune inflammation in the allograft heart. Sci. Rep. 2016, 7, 20077. [CrossRef]

28. Yang, C.; Kim, S.H.; Bianco, N.R.; Robbins, P.D. Tumor-derived exosomes confer antigen-specific immunosuppression in a murine delayed-type hypersensitivity model. PLoS ONE 2011, 6, e22517. [CrossRef]

29. Smyth, L.A.; Ratnasothy, K.; Tsang, J.Y.; Boardman, D.; Warley, A.; Lechler, R.; Lombardi, G. CD73 expression on extracellular vesicles derived from CD4+CD25+ Foxp3+ T cells contributes to their regulatory function. Eur. J. Immunol. 2013, 43, 2430-2440. [CrossRef]

30. Nazimek, K.; Bryniarski, K.; Askenase, P.W. Functions of exosomes and microbial extracellular vesicles in allergy and contact and delayed-type hypersensitivity. Int. Arch. Allergy Immunol. 2016, 171, 1-26. [CrossRef]

31. Tang, X.J.; Sun, X.Y.; Huang, K.M.; Zhang, L.; Yang, Z.S.; Zou, D.D.; Wang, B.; Warnock, G.L.; Dai, L.J.; Luo, J. Therapeutic potential of CAR-T cell-derived exosomes: A cell-free modality for targeted cancer therapy. Oncotarget 2015, 6, 44179-44190. [CrossRef] [PubMed]

32. Jackson, H.J.; Brentjens, R.J. Overcoming antigen escape with CAR T-cell therapy. Cancer Discov. 2015, 5, 1238-1240. [CrossRef] [PubMed]

33. Memarnejadian, A.; Meilleur, C.E.; Shaler, C.R.; Khazaie, K.; Bennink, J.R.; Schell, T.D.; Haeryfar, S.M.M. PD-1 blockade promotes epitope spreading in anticancer CD8+ T cell responses by preventing fratricidal death of subdominant clones to relieve immunodomination. J. Immunol. 2017, 199, 3348-3359. [CrossRef] [PubMed]

34. Sotillo, E.; Barrett, D.M.; Black, K.L.; Bagashev, A.; Oldridge, D.; Wu, G.; Sussman, R.; Lanauze, C.; Ruella, M.; Gazzara, M.R.; et al. Convergence of acquired mutations and alternative splicing of CD19 enables resistance to CART-19 immunotherapy. Cancer Discov. 2015, 5, 1282-1295. [CrossRef]

35. Whiteside, T.L. The potential of tumor-derived exosomes for noninvasive cancer monitoring. Expert Rev. Mol. Diagn. 2015, 15, 1293-1310. [CrossRef]

36. Kim, S.M.; Yang, Y.; Oh, S.J.; Hong, Y.; Seo, M.; Jang, M. Cancer-derived exosomes as a delivery platform of CRISPR/Cas9 confer cancer cell tropism-dependent targeting. J. Control. Release 2017, 266, 8-16. [CrossRef]

37. Redegeld, F.A.; van der Heijden, M.W.; Kool, M.; Heijdra, B.M.; Garssen, J.; Kraneveld, A.D.; Van Loveren, H.; Roholl, P.; Saito, T.; Verbeek, J.S.; et al. Immunoglobulin-free light chains elicit immediate hypersensitivity-like responses. Nat. Med. 2002, 8, 694-701. [CrossRef]

38. Yu, Y.; Blokhuis, B.R.; Garssen, J.; Redegeld, F.A. Non-IgE mediated mast cell activation. Eur. J. Pharmacol. 2016, 778, 33-43. [CrossRef]

39. Groot Kormelink, T.; Askenase, P.W.; Redegeld, F.A.M. Immunobiology of antigen-specific immunoglobulin free light chains in chronic inflammatory diseases. Curr. Pharm. Des. 2012, 18, 2278-2289. [CrossRef]

40. Carayon, K.; Chaoui, K.; Ronzier, E.; Lazar, I.; Bertrand-Michel, J.; Roques, V.; Balor, S.; Terce, F.; Lopez, A.; Salomé, L.; et al. Proteolipidic composition of exosomes changes during reticulocyte maturation. J. Biol. Chem. 2011, 286, 34426-34439. [CrossRef]

41. Mulcahy, L.A.; Pink, R.C.; Carter, D.R.F. Routes and mechanisms of extracellular vesicle uptake. J. Extracell. Vesicles 2014, 3, 1-14. [CrossRef] [PubMed]

42. Sato, Y.T.; Umezaki, K.; Sawada, S.; Mukai, S.; Sasaki, Y.; Harada, N.; Shiku, H.; Akiyoshia, K. Engineering hybrid exosomes by membrane fusion with liposomes. Sci. Rep. 2016, 6, 21933. [CrossRef] [PubMed] 
43. Hutchinson, A.T.; Ramsland, P.A.; Jones, D.R.; Agostino, M.; Lund, M.E.; Jennings, C.V.; Bockhorni, V.; Yuriev, E.; Edmundson, A.B.; Raison, R.L. Free Ig light chains interact with sphingomyelin and are found on the surface of myeloma plasma cells in an aggregated form. J. Immunol. 2010, 185, 4179-4188. [CrossRef] [PubMed]

44. Hutchinson, A.T.; Jones, D.R.; Raison, R.L. The ability to interact with cell membranes suggests possible biological roles for free light chain. Immunol. Lett. 2012, 142, 75-77. [CrossRef] [PubMed]

45. Hutchinson, A.T.; Malik, A.; Berkahn, M.B.; Agostino, M.; To, J.; Tacchi, J.L.; Djordjevic, S.P.; Turnbull, L.; Whitchurch, C.B.; Edmundson, A.B.; et al. Formation of assemblies on cell membranes by secreted proteins: Molecular studies of free $\lambda$ light chain aggregates found on the surface of myeloma cells. Biochem. J. 2013, 454, 479-489. [CrossRef] [PubMed]

46. Tan, S.M.; Lieberman, J. Capture and identification of miRNA targets by biotin pulldown and RNA-seq. Methods Mol. Biol. 2016, 1358, 211-228. [CrossRef]

47. Guo, Y.E.; Steitz, J.A. 3'-biotin-tagged microRNA-27 does not associate with Argonaute proteins in cells. RNA 2014, 20, 985-988. [CrossRef]

48. Admyre, C.; Johansson, S.M.; Qazi, K.R.; Filén, J.J.; Lahesmaa, R.; Norman, M.; Neve, E.P.; Scheynius, A.; Gabrielsson, S. Exosomes with immune modulatory features are present in human breast milk. J. Immunol. 2007, 179, 1969-1978. [CrossRef]

49. Gu, Y.; Li, M.; Wang, T.; Liang, Y.; Zhong, Z.; Wang, X.; Zhou, Q.; Chen, L.; Lang, Q.; He, Z.; et al. Lactation-related microRNA expression profiles of porcine breast milk exosomes. PLoS ONE 2012, 7, e43691. [CrossRef]

50. Hata, T.; Murakami, K.; Nakatani, H.; Yamamoto, Y.; Matsuda, T.; Aoki, N. Isolation of bovine milk-derived microvesicles carrying mRNAs and microRNAs. Biochem. Biophys. Res. Commun. 2010, 396, 528-533. [CrossRef]

51. Benmoussa, A.; Lee, C.H.; Laffont, B.; Savard, P.; Laugier, J.; Boilard, E.; Gilbert, C.; Fliss, I.; Provost, P. Commercial dairy cow milk microRNAs resist digestion under simulated gastrointestinal tract conditions. J. Nutr. 2016, 146, 2206-2215. [CrossRef]

52. Izumi, H.; Kosaka, N.; Shimizu, T.; Sekine, K.; Ochiya, T.; Takase, M. Bovine milk contains microRNA and messenger RNA that are stable under degradative conditions. J. Dairy Sci. 2012, 95, 4831-4841. [CrossRef]

53. Pieters, B.C.; Arntz, O.J.; Bennink, M.B.; Broeren, M.G.; van Caam, A.P.; Koenders, M.I.; van Lent, P.L.; van den Berg, W.B.; de Vries, M.; van der Kraan, P.M.; et al. Commercial cow milk contains physically stable extracellular vesicles expressing immunoregulatory TGF- $\beta$. PLoS ONE 2015, 10, e0121123. [CrossRef]

54. Irmak, M.K.; Oztas, Y.; Oztas, E. Integration of maternal genome into the neonate genome through breast milk mRNA transcripts and reverse transcriptase. Theor. Biol. Med. Model. 2012, 9, 20. [CrossRef] [PubMed]

55. Munch, E.M.; Harris, R.A.; Mohammad, M.; Benham, A.L.; Pejerrey, S.M.; Showalter, L.; Hu, M.; Shope, C.D.; Maningat, P.D.; Gunaratne, P.H.; et al. Transcriptome profiling of microRNA by Next-Gen deep sequencing reveals known and novel miRNA species in the lipid fraction of human breast milk. PLOS ONE 2013, 8, e50564. [CrossRef] [PubMed]

56. Kusuma, R.J.; Manca, S.; Friemel, T.; Sukreet, S.; Nguyen, C.; Zempleni, J. Human vascular endothelial cells transport foreign exosomes from cow's milk by endocytosis. Am. J. Physiol. Cell Physiol. 2016, 310, C800-C807. [CrossRef] [PubMed]

57. Wolf, T.; Baier, S.R.; Zempleni, J. The intestinal transport of bovine milk exosomes is mediated by endocytosis in human colon carcinoma caco-2 cells and rat small intestinal IEC-6 cells. J. Nutr. 2015, 145, 2201-2206. [CrossRef]

58. Hock, A.; Miyake, H.; Li, B.; Lee, C.; Ermini, L.; Koike, Y.; Chen, Y.; Määttänen, P.; Zani, A.; Pierro, A. Breast milk-derived exosomes promote intestinal epithelial cell growth. J. Pediatr. Surg. 2017, 52, 755-759. [CrossRef]

59. Parigi, S.M.; Eldh, M.; Larssen, P.; Gabrielsson, S.; Villablanca, E.J. Breast milk and solid food shaping intestinal immunity. Front. Immunol. 2015, 6, 415. [CrossRef] 
60. Manca, S.; Giraud, D.; Zempleni, J. Bioavailability and biodistribution of fluorophore-labeled exosomes from cow's milk after intravenous and oral administration in C57 Bl/6 J mice. FASEB J. 2016, 30 (Suppl. 1), 690.8. [CrossRef]

61. Izumi, H.; Tsuda, M.; Sato, Y.; Kosaka, N.; Ochiya, T.; Iwamoto, H.; Namba, K.; Takeda, Y. Bovine milk exosomes contain microRNA and mRNA and are taken up by human macrophages. J. Dairy Sci. 2015, 98, 2920-2933. [CrossRef] [PubMed]

62. Kosaka, N.; Izumi, H.; Sekine, K.; Ochiya, T. microRNA as a new immune-regulatory agent in breast milk. Silence 2010, 1, 1-8. [CrossRef] [PubMed]

63. Melnik, B.C.; John, S.M.; Schmitz, G. Milk: An exosomal microRNA transmitter promoting thymic regulatory T cell maturation preventing the development of atopy? J. Transl. Med. 2014, 12, 43. [CrossRef]

64. Torregrosa Paredes, P.; Gutzeit, C.; Johansson, S.; Admyre, C.; Stenius, F.; Alm, J.; Scheynius, A.; Gabrielsson, S. Differences in exosome populations in human breast milk in relation to allergic sensitization and lifestyle. Allergy 2014, 69, 463-471. [CrossRef]

65. Oliveira, M.C.; Arntz, O.J.; Blaney Davidson, E.N.; van Lent, P.L.; Koenders, M.I.; van der Kraan, P.M.; van den Berg, W.B.; Ferreira, A.V.; van de Loo, F.A. Milk extracellular vesicles accelerate osteoblastogenesis but impair bone matrix formation. J. Nutr. Biochem. 2016, 30, 74-84. [CrossRef] [PubMed]

66. Oliveira, M.C.; Di Ceglie, I.; Arntz, O.J.; van den Berg, W.B.; van den Hoogen, F.H.J.; Ferreira, A.V.M.; van Lent, P.L.E.M.; van de Loo, F.A.J. Milk-derived nanoparticle fraction promotes the formation of small osteoclasts but reduces bone resorption. J. Cell. Physiol. 2017, 232, 225-233. [CrossRef] [PubMed]

67. Title, A.C.; Denzler, R.; Stoffel, M. Uptake and function studies of maternal milk-derived microRNAs. J. Biol. Chem. 2015, 290, 23680-23691. [CrossRef]

68. Hirschi, K.D.; Pruss, G.J.; Vance, V. Dietary delivery: A new avenue for microRNA therapeutics? Trends Biotechnol. 2015, 33, 431-432. [CrossRef]

69. Zempleni, J. Milk exosomes: Beyond dietary microRNAs. Genes Nutr. 2017, 12, 12. [CrossRef]

70. Zhang, L.; Hou, D.; Chen, X.; Li, D.; Zhu, L.; Zhang, Y.; Li, J.; Bian, Z.; Liang, X.; Cai, X.; et al. Exogenous plant MIR168 a specifically targets mammalian LDLRAP1: Evidence of cross-kingdom regulation by microRNA. Cell Res. 2012, 22, 107-126. [CrossRef]

71. Auerbach, A.; Vyas, G.; Li, A.; Halushka, M.; Witwer, K. Uptake of dietary milk miRNAs by adult humans: A validation study. F1000 Res. 2016, 5, 721. [CrossRef] [PubMed]

72. Dickinson, B.; Zhang, Y.; Petrick, J.S.; Heck, G.; Ivashuta, S.; Marshall, W.S. Lack of detectable oral bioavailability of plant microRNAs after feeding in mice. Nat. Biotechnol. 2013, 31, 965-967. [CrossRef]

73. Snow, J.W.; Hale, A.E.; Isaacs, S.K.; Baggish, A.L.; Chan, S.Y. Ineffective delivery of diet-derived microRNAs to recipient animal organisms. RNA Biol. 2013, 10, 1107-1116. [CrossRef] [PubMed]

74. Witwer, K.W.; Zhang, C.-Y. Diet-derived microRNAs: Unicorn or silver bullet? Genes Nutr. 2017, 12, 15. [CrossRef]

75. Liang, H.; Zhang, S.; Fu, Z.; Wang, Y.; Wang, N.; Liu, Y.; Zhao, C.; Wu, J.; Hu, Y.; Zhang, J.; et al. Effective detection and quantification of dietetically absorbed plant microRNAs in human plasma. J. Nutr. Biochem. 2015, 26, 505-512. [CrossRef]

76. Mateescu, B.; Kowal, E.J.; van Balkom, B.W.; Bartel, S.; Bhattacharyya, S.N.; Buzás, E.I.; Buck, A.H.; de Candia, P.; Chow, F.W.; Das, S.; et al. Obstacles and opportunities in the functional analysis of extracellular vesicle RNA-An ISEV position paper. J. Extracell. Vesicles 2017, 6, 1286095. [CrossRef]

77. Perge, P.; Nagy, Z.; Decmann, A.; Igaz, I.; Igaz, P. Potential relevance of microRNAs in inter-species epigenetic communication, and implications for disease pathogenesis. RNA Biol. 2016, 14, 391-401. [CrossRef]

78. Tosar, J.P.; Cayota, A.; Eitan, E.; Halushka, M.K.; Witwer, K.W. Ribonucleic artefacts: Are some extracellular RNA discoveries driven by cell culture medium components? J. Extracell. Vesicles 2017, 6, 1272832. [CrossRef]

79. Wasik, M.; Nazimek, K.; Nowak, B.; Askenase, P.W.; Bryniarski, K. Delayed-type hypersensitivity underlying casein allergy is suppressed by extracellular vesicles carrying miRNA-150. Nutrients 2019, 11, 907. [CrossRef]

80. Tsuji, R.F.; Szczepanik, M.; Kawikova, I.; Paliwal, V.; Campos, R.A.; Itakura, A.; Akahira-Azuma, M.; Baumgarth, N.; Herzenberg, L.A.; Askenase, P.W. B cell-dependent T cell responses. IgM antibodies are required to elicit contact sensitivity. J. Exp. Med. 2002, 196, 1277-1290. [CrossRef] 
81. Nazimek, K.; Bustos-Morán, E.; Blas-Rus, N.; Nowak, B.; Ptak, W.; Askenase, P.W.; Sánchez-Madrid, F.; Bryniarski, K. Syngeneic red blood cell-induced extracellular vesicles suppress delayed-type hypersensitivity to self-antigens in mice. Clin. Exp. Allergy 2019, 49, 1487-1499. [CrossRef] [PubMed]

82. Kowal, J.; Arras, G.; Colombo, M.; Jouve, M.; Morath, J.P.; Primdal-Bengtson, B.; Dingli, F.; Loew, D.; Tkach, M.; Théry, C. Proteomic comparison defines novel markers to characterize heterogeneous populations of extracellular vesicle subtypes. Proc. Natl. Acad. Sci. USA 2016, 113, E968-E977. [CrossRef] [PubMed]

(C) 2020 by the authors. Licensee MDPI, Basel, Switzerland. This article is an open access article distributed under the terms and conditions of the Creative Commons Attribution (CC BY) license (http://creativecommons.org/licenses/by/4.0/). 